\title{
The influence of lipid content and lipoxygenase on flavor volatiles in the tomato peel and flesh
}

\section{THESIS}

Presented in Partial Fulfillment of the Requirements for the Degree Master of Science in the Graduate School of The Ohio State University

\author{
By \\ Paige Ties, B.S. \\ Graduate Program in Food Science and Technology \\ The Ohio State University \\ 2012 \\ M.S. Committee: \\ Dr. Sheryl Barringer, Advisor \\ Dr. John Litchfield \\ Dr. Luis Rodriguez-Saona
}




\section{Copyrighted by}

\section{Paige Ties}

2012 


\begin{abstract}
Ten different varieties of tomatoes were separated into peel and flesh and each portion was measured separately. Headspace volatiles were measured in real time using selected ion flow tube mass spectrometry (SIFT-MS). Lipoxygenase activity was measured using the adsorption of conjugated dienes formed by lipoxygenase. Lipid was extracted and fatty acids were quantified using a gas chromatograph. Volatiles were significantly greater in the peel than flesh when there was a significant difference. The lipoxygenase activity of the flesh and peel correlated with the volatiles produced by the lipoxygenase pathway. There was no correlation with the other volatiles, which are not dependent on lipid oxidation by lipoxygenase. The lipoxygenase activity, total fatty acid content, and linolenic acid of the peel was greater than the flesh, which is directly related to an increase in fresh, green volatiles. Addition of exogenous lipoxygenase had no effect on lipoxygenase derived volatiles formed in the peel and flesh. The addition of linoleic acid caused an increase in hexanal, 1-hexanol, and (E)-2-heptenal in the flesh and (E)-2heptenal in the peel. Stored unrefrigerated peel had higher volatile concentrations whereas refrigerated peel had significantly lower concentration than Day 0. Storage decreased lipoxygenase activity in the unrefrigerated and refrigerated peel, but had no effect on the fatty acid content. Overall, linolenic acid was the most important to the
\end{abstract}


formation of headspace volatiles, but lipoxygenase activity and unknown factors are also important.

\section{Practical Applications}

The peel of a tomato is most beneficial to the production of volatiles associated with the fresh aroma of tomatoes; therefore, should be used in the processing of tomato products to produce a fresh, green aroma rather than being removed. Knowledge of the effects of lipoxygenase activity, total fatty acid content, and fatty acid profile on flavor volatiles will allow for better selection of a variety for raw consumption. 
Dedicated to my family and friends 


\section{Acknowledgments}

I would like to start off by thanking my advisor, Dr. Sheryl Barringer for her endless amounts of support and guidance. She taught me how to properly write a research paper, and learn from the difficulties that arise in research. The lessons I have learned from her will stay with me as I progress into industry.

Secondly, I would like to thank my committee members, Dr. Luis RodriguezSaona and Dr. John Litchfield for their willingness to help me with any questions I had and their continual interest in my research and education.

I will never be able to fully express my gratitude for my parents, Mark and Kristi Ties, for their unconditional love and support. They taught me to always strive for greatness no matter the situation and to never let the difficult times bring me down. For all the sacrifices they have made for me, I cannot thank them enough.

Lastly, thank you to my friends and lab mates for their friendship and all of their support and encouragement. 


\section{Vita}

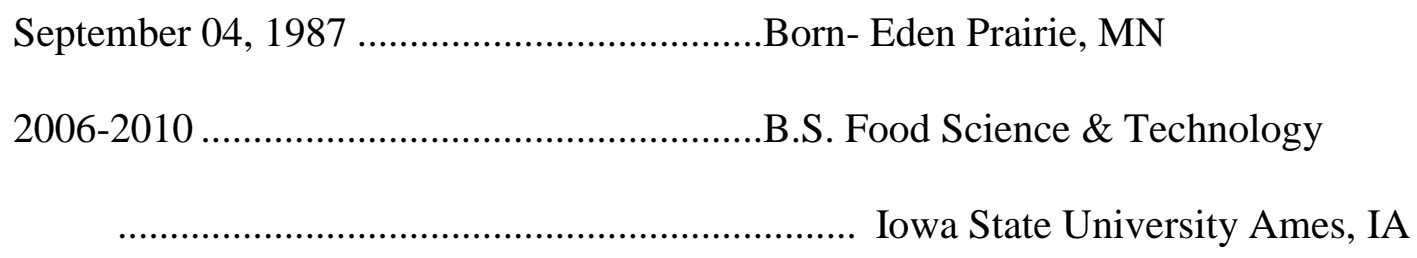

Fields of Study

Major Field: Food Science \& Technology 


\section{Table of Contents}

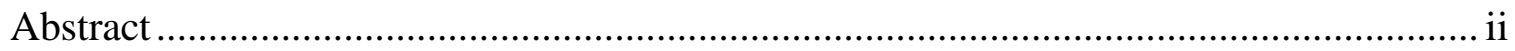

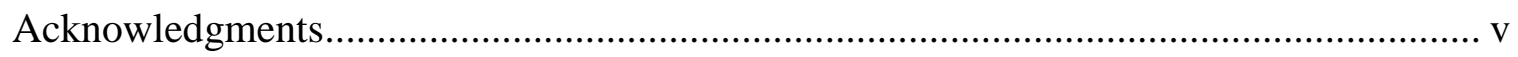

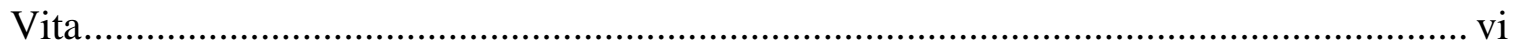

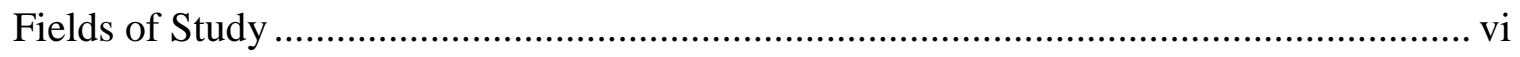

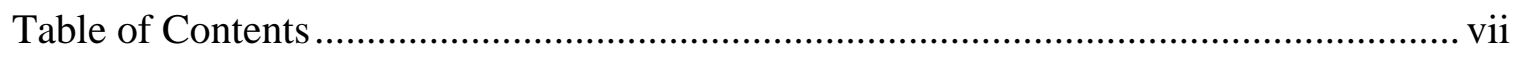

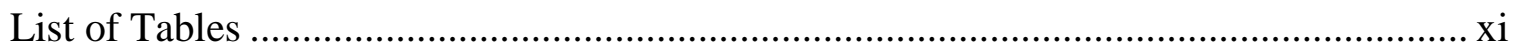

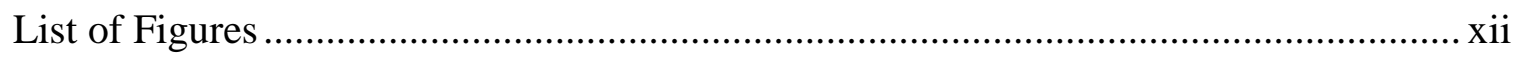

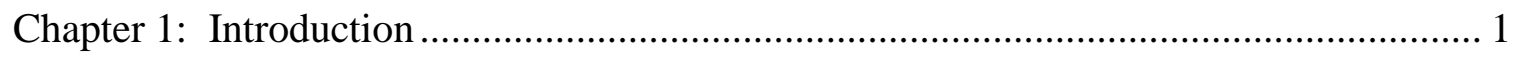

Chapter 2: Literature Review ........................................................................... 5

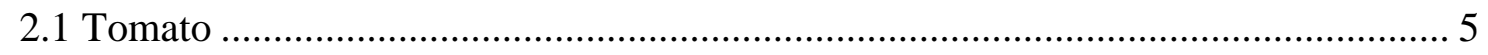

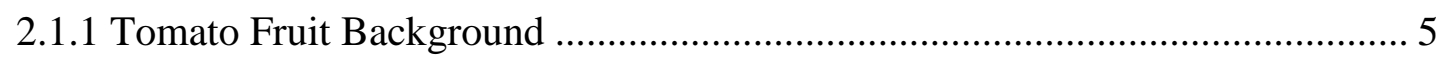

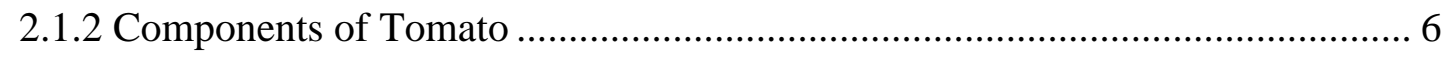

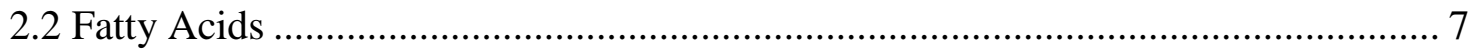

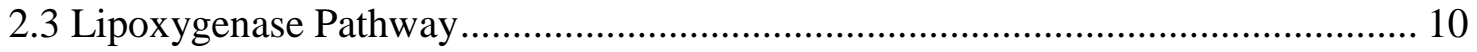

vii 
2.3.1 Lipoxygenase Pathway in the Formation of Tomato Volatiles ..... 10

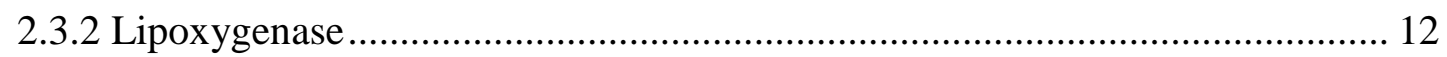

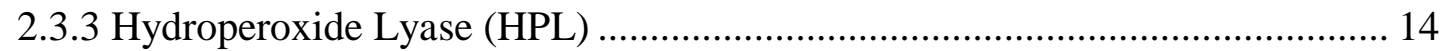

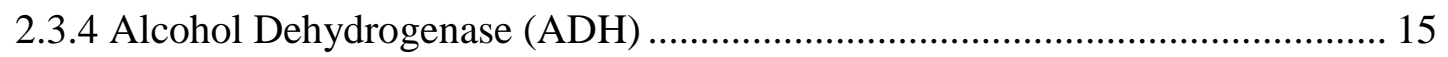

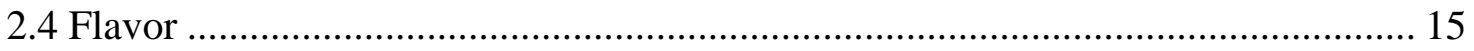

2.4.1 Tomato Volatiles ................................................................................. 15

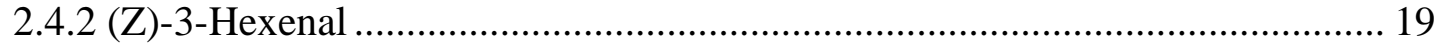

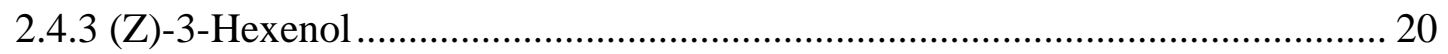

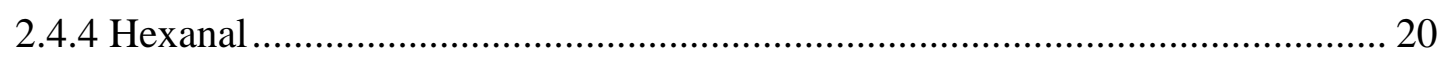

2.4.5 1-Penten-3-one and (E)-2-Pentenal ........................................................ 21

2.4.6 3-Methylbutanal and Phenylacetaldehyde................................................. 21

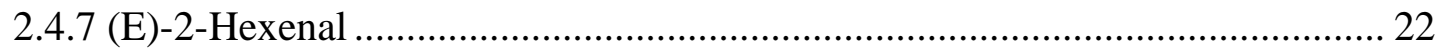

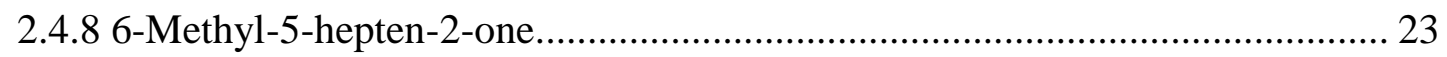

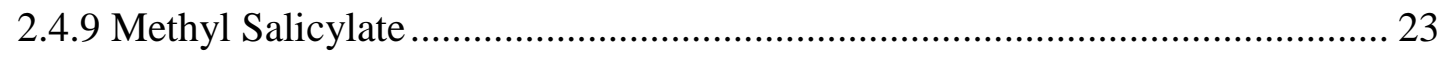

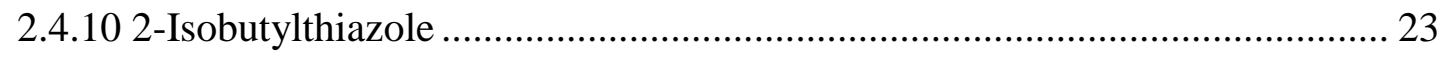

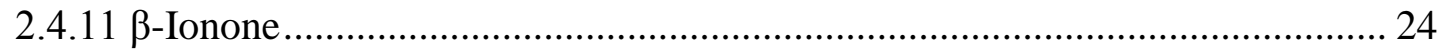

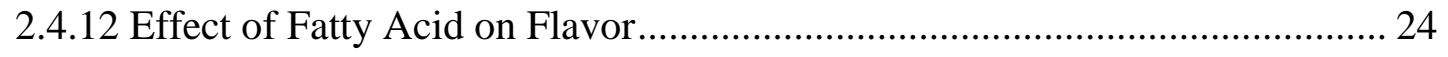

2.4.13 Effect of Lipoxygenase on Flavor ...................................................... 25

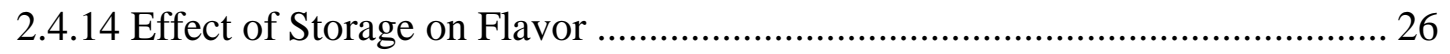


2.5 Analytical Methods for Headspace Analysis

2.6 Selected Ion Flow Tube Mass Spectrometry (SIFT-MS) ................................... 28

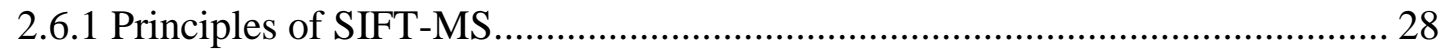

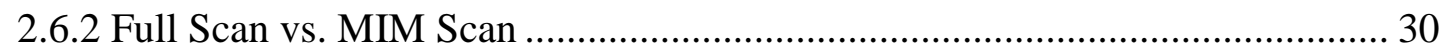

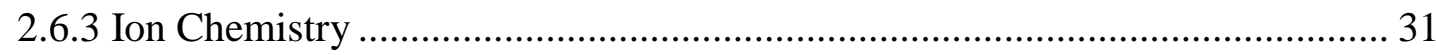

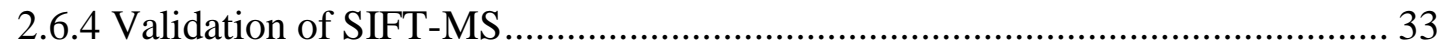

2.6.5 Application of SIFT-MS in Food Science .............................................. 33

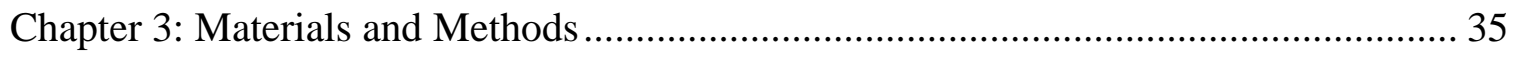

3.1 Headspace Volatile Quantification................................................................. 35

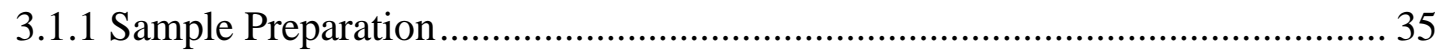

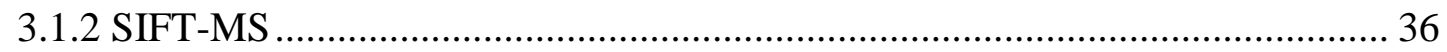

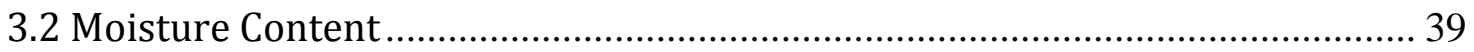

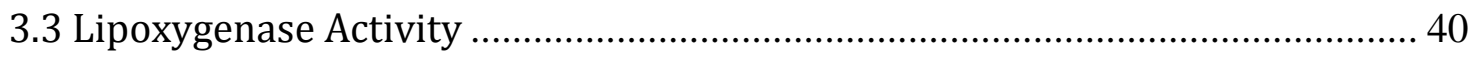

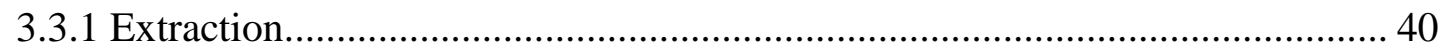

3.3.2 Lipoxygenase Activity Quantification.................................................. 41

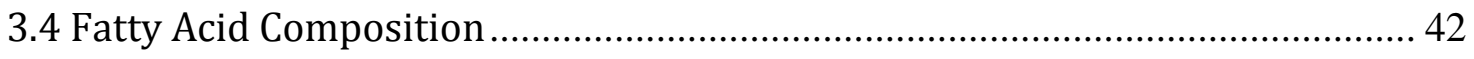

3.4.1 Lipid Extraction and Total Fatty Acid Determination................................. 42

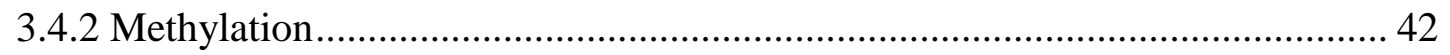

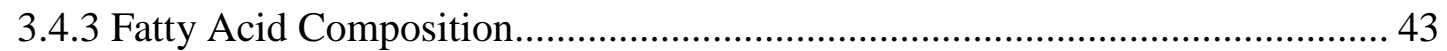

ix 
3.6 Addition of Lipoxygenase and Linoleic Acid ...................................................... 44

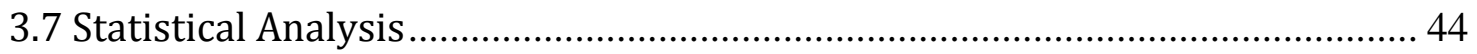

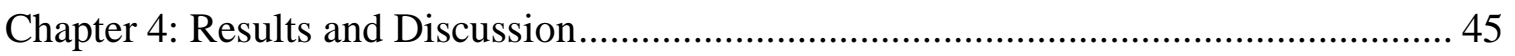

4.1 Comparison of Peel and Flesh of Tomato ......................................................... 45

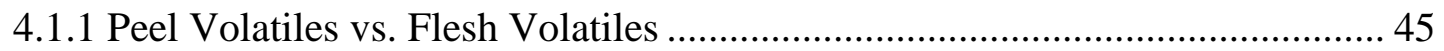

4.1.2 Effect of Lipoxygenase Activity on Volatile Concentration ............................. 52

4.1.3 Effect of Total Fatty Acid Content and Fatty Acid Profile on Volatile

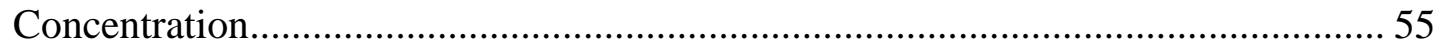

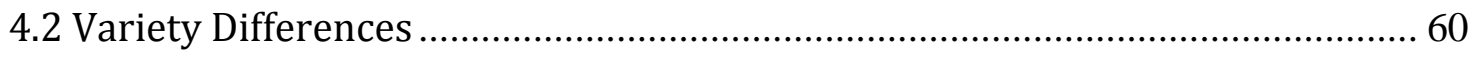

4.3 Effect of Storage Temperature on Volatiles ....................................................... 62

4.3.1 Day 0 vs. Day 14 Unrefrigerated and Refrigerated Storage ............................. 62

4.3.2 Storage Effects on Lipoxygenase Activity and Fatty Acid Content.................. 63

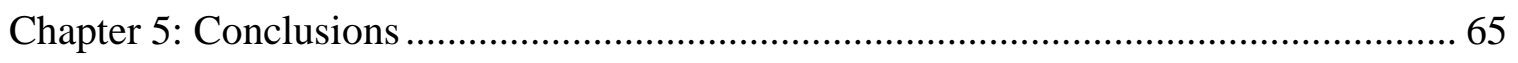

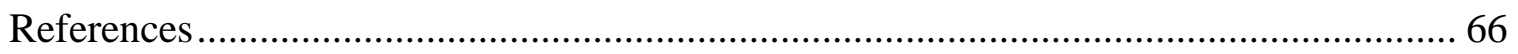




\section{List of Tables}

Table 2.1 Tomato Composition ............................................................................... 7

Table 2.2 Tomato Fatty Acid Profile ............................................................................ 8

Table 3.1 Reaction kinetics of the selected volatile compounds measured in the

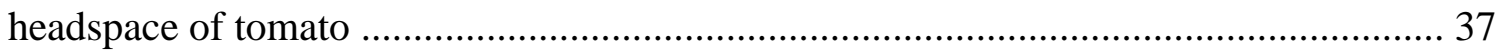

Table 3.2 Weights of Tomato for Lipid Extraction ................................................ 40

Table 4.1 Peel volatiles (ppm) of 10 tomato volatiles ............................................. 48

Table 4.2 Flesh volatiles (ppm) of 10 tomato varieties ........................................... 50

Table 4.3 Lipoxygenase activity (nmol/g fwt/min) in different varieties of tomato ........53

Table 4.4 Effect of lipoxygenase addition on the lipoxygenase generated volatile ........ 55

Table 4.5 Total fatty acid content ( $\mathrm{g} / \mathrm{fwt} \mathrm{kg})$ of different tomato varieties ................... 56

Table 4.6 Fatty acid profiles $(\%)$ of different tomato varieties ................................... 57

Table 4.7 Effect of linoleic acid addition on the formation of linoleic acid derived

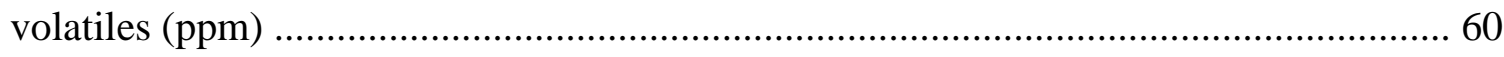

Table 4.8 Effect of storage temperature on flesh and peel volatile production (ppm) .... 63

Table 4.9 Effect of storage temperature on flesh and peel lipoxygenase activity (nmol/g

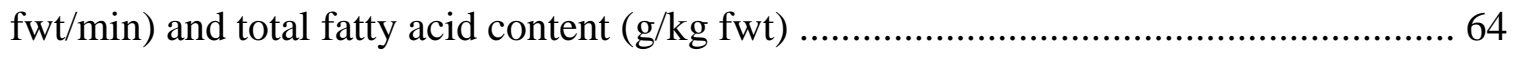




\section{List of Figures}

Figure 2.1 Lipoxygenase pathway of linoleic and linolenic acids in tomato .................. 12

Figure 2.2 Principles of Selected Ion Flow Tube Mass Spectrometry ......................... 29

Figure 4.1 Effect of lipoxygenase activity on (Z)-3-hexenal formation in flesh and

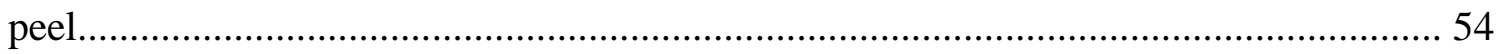

Figure 4.2 Effect of total fatty acid content and linolenic acid on (Z)-3-hexenal formation

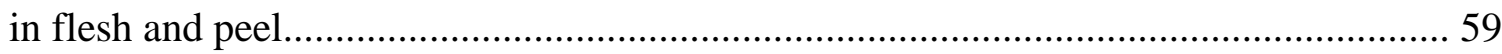




\section{Chapter 1: Introduction}

Flavor is the critical quality characteristic in acceptance of fresh tomatoes and due to this fact consumers are willing to pay a premium for full-flavored fruit (Baldwin and

others 2000). There have been over 400 flavor volatiles identified in tomato (Petro-Turza 1987), although the combination of 10 of these volatiles at varying concentrations produces the aroma of a fresh, ripe tomato (Buttery 1993). A majority of these volatiles are lipid derived and originate from the lipoxygenase pathway. This pathway is a cascade of enzymatic reactions that predominately form C-6 volatile compounds. The main enzymes involved are lipoxygenase (LOX), hydroperoxide lyase (HPL), alcohol dehydrogenase (ADH), isomerase, and lipase (Galliard and Matthew 1977). Stone and others (1975) were the first to propose the pathway that starts with tomato acyl lipids being broken down into free fatty acids, most importantly linoleic acid and linolenic acid. These fatty acids then react with LOX and HPL to form hexanal and (Z)-3-hexenal. (Z)3-Hexenal is isomerized by $(Z)-3 /(E)-2$ isomerase to form $(E)$-2-hexenal. ADH then converts these aldehydes into alcohols. There are other rearrangement reactions with 
unknown enzymes that form $(E)$-2-octenal, $(E)$-2-heptenal, $(E)$-2-pentenal and 1-penten3-one.

Different tissues of fruits and vegetables contain varying concentrations of flavor volatiles. Buttery and others (1988) analyzed a tomato broken down into four parts: pulp, skin, fluid, and seeds. The pulp contains similar values to the whole tomato except for higher levels of $(E)$-2-hexenal and C6 alcohols. The skin made up 10\% of the whole tomato; however, it contained considerably higher levels of C6 aldehydes and severalfold higher concentrations of $\mathrm{C} 6$ alcohols than the whole tomato or the interior pulp. The concentrations in the fluid and seeds were generally lower. The reason for the difference in volatile concentrations in different tissues is not known, but lipoxygenase and fatty acid content are likely causes due to their role in the production of these volatiles.

The lipoxygenase pathway is the main creator of green, fresh volatiles in fruits and vegetables; therefore the level of lipoxygenase activity is important. The locular material has no lipoxygenase activity, while the skin with outer flesh has $71 \%$ of the activity, but when the flesh was removed from the skin the activity was drastically lower for the relatively pure skin (Hatanaka and others 1992). This suggests that lipoxygenase activity is greatest in the fleshy tissue adjacent to the skin. When an exogenous lipoxygenase, alcohol dehydrogenase or lipoxygenase/alcohol dehydrogenase was added, there was a steady decrease, not the expected increase, in the concentrations of hexanal, (Z)-3-hexenal, (E)-2-hexenal and 1-penten-3-one with the addition treatments (Yilmaz and others 2002). There are some inconsistencies in volatile results as researchers have 
also found that decreasing the levels of lipoxygenase leads to a large reduction in fatty acid derived volatile aldehydes and alcohols in tomatoes (Chen and others 2004).

Fatty acids make up a very small portion of a tomato yet they are the precursors for the lipid derived volatiles formed in the lipoxygenase pathway (Petro-Turza 1987). To test the effect of fatty acid concentrations on lipid derived volatiles, there were tomato cultivars bred to contain different levels of linoleic and linolenic acids. When the ratio of linoleic acid to linolenic acid is higher there was a significant increase in the hexanal to hexenal ratio (Gray and others 1999). Similar findings were found when the expression of a yeast $\Delta-9$ desaturase gene was altered to produce higher concentrations of oleic acid, linoleic acid, and total fatty acid concentration. Hexanal and 1-hexanol were more than two times greater in the tomato with higher levels of fatty acids than the control (Wang and others 1996). By altering the Spr2 gene higher levels of linoleic acid were created and lower levels of linolenic acid formed, which caused an increase in hexanal and a decrease in (Z)-3-hexenal (Canoles and others 2006). Certain fatty acids have been found to correlate with the formation of some of their successor flavor volatiles.

Tomato volatiles have been previously studied using a gas chromatograph-mass spectrometer, atmospheric pressure ionization mass spectrometer, proton transfer reaction mass spectrometer and selected ion flow tube mass spectrometer (SIFT-MS) (Beltran and others 2006, Xu and Barringer 2009). The SIFT-MS is a relatively new technique for quantifying volatiles in tomatoes although it is able to do real time analysis and differentiate isomers without preconcentration, which the other methods cannot always do (Spanel and Smith 1999). This technique has been used in medical diagnosis (Smith 
and others 2003b), monitoring environmental gas emission (Wilson and others 2003), as well as analysis of food, flavor and fragrance (Frank 2007). SIFT-MS has been useful in monitoring the real time release of food volatiles in oxidation of food products (Davis and others 2007), breathe analysis (Hansanugrum and Barringer 2009), enzyme activity (Azcarte and Barringer 2010), and roasting (Huang and Barringer 2011).

Tomato varieties differ in lipoxygenase activity, total fatty acid content, and fatty acid profile. These differences can have an impact on volatiles formed from raw tomatoes. The objective is to compare the peel and the flesh volatile concentrations and correlate these levels with lipoxygenase activity, total fatty acid content and individual fatty acids. 


\section{Chapter 2: Literature Review}

\subsection{Tomato}

\subsubsection{Tomato Fruit Background}

Tomato (Solanum lycopersicum) belongs to the Solanaceae family where it is botanically classified as a fruit but is consumed as a vegetable. The Solanum genus has only eight species and two subgenerations with the tomatoes cultivated mainly belonging to the Eulycopersicon subgeneration (Petro-Turza 1987). There are around 7500 varieties grown for numerous reasons, including tomato paste, sauces and consumed raw. Plum tomatoes are a variety bred for higher solids content, which makes them useful for paste and sauce applications. On the other hand, beefsteak and grape tomatoes tend to be consumed raw. Tomatoes come in a variety of circular or oblong shapes and weigh anywhere from $1 \mathrm{oz}$ to over $16 \mathrm{oz}$ (Wolford and Banks 2011). Overall, United States is the second largest producer of tomatoes which accounts for $50.7 \%$ of the economic value of processed vegetables and $14.5 \%$ of the economic value of fresh market vegetables (Robertson and Labate 2007). This also makes tomato one of the most economically valuable crops in the United States (U.S. Department of Agriculture 2008). 


\subsubsection{Components of Tomato}

Tomatoes vary greatly from fruit-to-fruit not only due to different cultivars but also between tomatoes from the same cultivar. The composition is quite variable depending on the cultivar but is also affected by the ripeness, year of growth and growing conditions. Due to tomato variation there are large fluctuations in published data (PetroTurza 1987). Current data shows considerable differences in the nosespace volatile concentrations both among tomatoes of the same type as well as between different types (Brauss and others 1998).

The components of tomatoes are believed to play at least some role in the characteristic flavor. Table 2.1 contains composition data for yearly average, red, ripe tomato from the USDA Food Composition Database (USDA 2010). The effect of each component can be direct, as in flavor substances, or indirect. The indirect effect can include catalyzing reactions, being a precursor to flavor compounds, absorption of some volatiles or a medium for reactions to occur. (Petro-Turza 1987). There were no significant differences in the soluble solids content between the locular and pericarp tissue in a variety of cultivars. No significant difference was also found in the $\mathrm{pH}$ of the locular and pericarp tissue of most varieties except two varieties that had higher $\mathrm{pH}$ values in the locule than the pericarp. This can be significant due to the $\mathrm{pH}$ effects on lipoxygenase activity (Stevens and others 1977). The sweet and sour taste as well as the differences in flavor of different genotypes is attributed to the concentration and ratio of sugars and organic acids. The variation in sweetness is due to the fructose concentration 
more than glucose. As for the organic acids, citric acid has more influence on tomato flavor than malic acid (Petro-Turza 1987).

Table 2.1 Tomato Composition (USDA 2010)

\begin{tabular}{|c|c|}
\hline Component & Percent Composition \\
\hline Water & $94.52 \%$ \\
\hline Protein & $0.88 \%$ \\
\hline Total Lipid & $0.20 \%$ \\
\hline Total Sugars & $2.63 \%$ \\
\hline
\end{tabular}

\subsection{Fatty Acids}

The fatty acid content of tomatoes varies depending on the variety. Gray and others (1999) found the total content of fatty acids on a fresh weight basis for cherry and standard tomatoes to be 0.0006 and $0.0005 \mathrm{~g} \mathrm{~g}^{-1}$, respectively. The USDA (2011) also reported that the fatty acid content on a fresh weight basis of an Roma tomato to be $0.0019 \mathrm{~g} \mathrm{~g}^{-1}$, Cherry tomato to be $0.0018 \mathrm{~g} \mathrm{~g}^{-1}$, and a plum tomato to be $0.0019 \mathrm{~g} \mathrm{~g}^{-1}$.

Poly-unsaturated fatty acids prevail with linoleic acid present at $40 \%$ and linolenic acid present at 26\% (Petro-Turza 1987), which are similar to the pericarp levels found by Bergevin and others (1993), (Table 2.2). These reported values vary greatly from the USDA values of $56.74 \%$ for linoleic acid and $2.13 \%$ for linolenic acid (USDA 
2010 ) and the pericarp levels found by Cook and others (2002) to be $62.71 \%$ for linoleic acid and $3.99 \%$ for linolenic acid.

Table 2.2 Tomato Fatty Acid Profiles

\begin{tabular}{|c|l|l|l|l|}
\hline Fatty Acid & \multicolumn{1}{|c|}{$\begin{array}{c}\text { Petro-Turza } \\
(\mathbf{1 9 8 7})\end{array}$} & $\begin{array}{c}\text { Bergevin and } \\
\text { others (1993) }\end{array}$ & USDA (2010) & $\begin{array}{c}\text { Cook and } \\
\text { others (2002) }\end{array}$ \\
\hline Palmitic (16:0) & N/A & $25.4 \%$ & $14.18 \%$ & $14.3 \%$ \\
\hline Stearic (18:0) & N/A & N/A & $5.67 \%$ & $3.72 \%$ \\
\hline Oleic (18:1) & N/A & $2.2 \%$ & $21.28 \%$ & $15.21 \%$ \\
\hline Linoleic (18:2) & $40 \%$ & $45.5 \%$ & $56.74 \%$ & $62.71 \%$ \\
\hline Linolenic (18:3) & $26 \%$ & $21.6 \%$ & $2.13 \%$ & $3.99 \%$ \\
\hline
\end{tabular}

The difference in values can be accounted for by a different cultivar being used, class of lipid measured, storage conditions as well as the known variation among individual tomatoes. A difference in cultivars was found between cherry and standard tomatoes. Cherry has higher levels of linolenic and oleic acids whereas standard tomato has higher concentrations of linoleic and stearic acids (Gray and others 1999). A difference in type of lipid was also found. Neutral lipids are present in higher amounts than phospholipids and glycolipids, respectively. Linolenic acid was present in higher concentrations in the neutral lipid whereas oleic and linoleic acid are greater in the phospholipid portion (Gray and others 1999). Storage studies have found that there is a 
decrease in linolenic acid concentration at $20^{\circ} \mathrm{C}$. This is accompanied by an increase in palmitic, oleic and linoleic acids (Bergevin and others 1993). The levels of lipids, lipases and lipoxygenase varied during the stages of development as well as variety and storage treatment. Linolenic, linoleic, oleic, stearic, and palmitic acids increased during the period of greatest color development (Kazeniac and Hall 1970).

Even though fatty acids are present in such small amounts they seem to be much more important precursors to volatiles than carbohydrates which make up more than $50 \%$ of dry matter. Upon maceration of tomato tissues, the enzymatic breakdown of lipids occurs very rapidly. The fatty acids are the precursor molecules in the lipoxygenase pathway, which produces volatiles important to the fresh, green aroma of tomatoes. Researchers have found the same essential oils present in all varieties of tomatoes, although there are variations in the concentrations of each fatty acid depending on the variety. It has been hypothesized that the differences in aroma between varieties could be due to the dissimilarity in quantity as well as the relative ratios of other components in tomatoes (Petro-Turza 1987).

A relationship between the relative amounts of tomato fatty acid and C6 aldehydes has been identified when comparing cherry and standard tomatoes. A standard tomato has approximately twice the fatty acid ratio and three times the $\mathrm{C} 6$ aldehyde ratio as a cherry tomato. In directly comparing the concentrations, hexanal and hexenal produced from macerated tomato have similar ratios to the relative composition of their precursor fatty acids, linoleic and linolenic acids, respectively (Gray and others 1999). Although when comparing the volatiles with tomato size, $(Z)$-3-hexenal and (E)-2- 
hexenal increase with decreasing size, whereas hexanal is less closely related with tomato size.

The fact that there is no overall increase in all of the lipid degradation products with size suggests that the lipid degradation pathway is specific, meaning there are differences in the metabolism of linoleic and linolenic fatty acids. Certain acyl hydrolase enzymes have been found to prefer to cleave more highly unstaturated fatty acid groups, monogalactosyldiacylglycerol and digalactosyldiacylglycerol, during chilling (Whitaker 1993). This correlates with the fact that more linolenic acid was lost upon maceration of tomato than linoleic acid (Gray and others 1999).

\subsection{Lipoxygenase Pathway}

\subsubsection{Lipoxygenase Pathway in the Formation of Tomato Volatiles}

The lipoxygenase pathway is known as a cascade of enzymatic reactions that predominately form C-6 volatile compounds. The main enzymes involved in this pathway are lipoxygenase, hydroperoxide lyase, alcohol dehydrogenase, isomerase, and lipase (Galliard and Matthew 1977). These enzymes are active during ripening but the actual synthesis of C6 volatile compounds is more prevalent when the tomato tissue has been disrupted. This allows for the enzyme and substrate to be properly mixed (Prestage and others 1999). The two significant substrates of these volatiles are linoleic and linolenic acids. Upon disruption of the tomato tissue, the reactions will begin by initially breaking down unsaturated fatty acids that in turn form important volatile compounds. These volatiles are responsible for the key characteristic taste and aroma in tomatoes. 
Lipoxygenase pathways have also been identified in many other fruits and vegetables although some of the pathways are more complicated.

The lipoxygenase pathway was first proposed by Stone and others (1975). The first lipid breakdown products that effect the odor and flavor are hexanal and (Z)-3hexenal. Linoleic and linolenic acid are converted to hexanal and (Z)-3-hexenal, respectively, by reaction with lipoxygenase (LOX) and hydroperoxide lyase (HPL). (Z)3-hexenal quickly isomerizes into (E)-2-hexenal by (Z)-3/(E)-2 isomerase (Z3/E2-ISO). Partly because of the limits of the experimental procedure, and partly because of the enzymatic activity occurring immediately upon maceration, it is difficult to establish which of the volatile components were present originally in the ripe fruit and which developed during processing (Petro-Turza 1987). But now with the addition of $\mathrm{CaCl}_{2}$ solutions, researchers have been able to identify the original concentrations by deactivating the enzymes (Buttery and Ling 1993b). Then the aldehyde group of (Z)-3hexenal and $(E)$-2-hexenal were reduced by alcohol dehydrogenase to form their alcohol counterparts. The lipoxygenase pathway produces the major C6 volatiles as well as $(E)$ 2-octenal, and (E)-2-heptenal from linoleic acid, as well as (E)-2-pentenal, and 1-penten3-one from linolenic acid. They are formed by unknown enzymes from 10hydroperoxides and 12-hydroperoxides, found in bell peppers (Luning and others 1995). Linolenic acid is also the precursor of $(E)$-2-pentenal and 1-penten-3-one in soybeans and bell peppers (Luning and others 1995). The formation of volatiles appears to go in a sequential fashion once the tomato tissue has been disrupted. There is a significant 
difference in the rate of formation of the aldehydes and alcohols. Aldehydes form first which are then the precursor molecules of the alcohols (Linforth and others 1996).

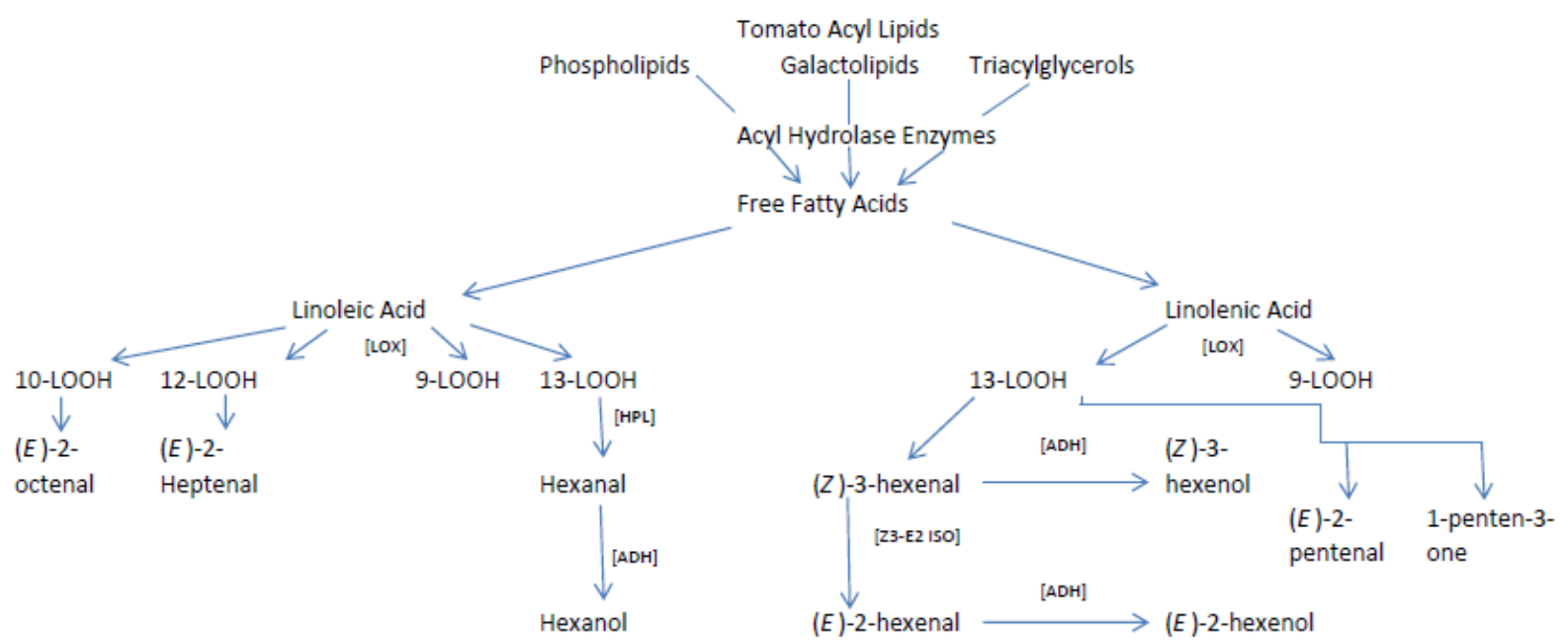

Figure 2.1 Lipoxygenase pathway of linoleic and linolenic acids in tomato. Abbreviations: LOOH, hydroperoxide; [LOX], tomato lipoxygenase; [HPL], hydroperoxide lyase; [ADH], alcohol dehydrogenase; [Z3-E2 ISO], cis-3/trans-2 isomerase (Stone and others 1975)

\subsubsection{Lipoxygenase}

Lipoxygenase (LOX) plays a key role in the development of C6 volatile compounds in tomatoes. LOX is a nonheme iron-containing dioxygenase that catalyzes the reaction of the addition of oxygen into polyunsaturated fatty acids that contain a

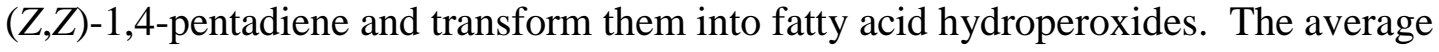
molecular weight of LOX is $96 \mathrm{kDa}$. LOX has an optimum $\mathrm{pH}$ range of 4.2-8.0 and an optimum temperature range of $20-30^{\circ} \mathrm{C}$ (Yilmaz 2001b). Not only is LOX important to flavor volatile creation it has also been found to be involved in plant growth and development, biosynthesis of regulatory molecules, insect attraction and defense, 
senescence, and response to wounding (Chen and others 2004). There are two classes of LOX enzymes: 9-LOX which forms 9-hydroperoxides, and 13-LOX which forms 13hydroperoxides (Hatanaka 1993). Consideration must be made to the fact that the key volatiles are only derived from 13-hydroperoxides not the more plentiful 9hydroperoxides. Of these two classes there are five LOX genes including Tomlox A, Tomlox B, Tomlox C, Tomlox D, and Tomlox E. The LOX isomers are different in their optimum $\mathrm{pH}$, substrate and product specificity, location, and synthesis at certain developmental stages (Chen and others 2004). Tomlox A, Tomlox B, and Tomlox E generate 9-hydroperoxides. There are little or no hydroperoxide lyases to act on the 9hydroperoxides therefore they accumulate and are not involved in the creation of C6 volatile compounds (Galliard and Matthew 1977). Tomlox D creates 13-hydroperoxides but does not play a role in creating C6 flavor compounds in tomatoes.

Studies by Chen and others (2004) found that decreasing the levels of Tomlox C led to a large reduction in fatty acid derived short chain volatile aldehydes and alcohols in tomatoes. Therefore, it is recognized that Tomlox $\mathrm{C}$ is the key isomer in the production of volatiles. Tomlox $\mathrm{C}$ is thought to be located in the chloroplast. The chloroplasts isolate LOX from other reactants in the lipoxygenase pathway so that may be why volatile production does not occur until the cells are disrupted. It has also been proposed that chloroplasts are the major site for fatty acid hydroperoxide metabolism. By disrupting the thylakoid membranes linoleic and linolenic acid may be produced. Consequently, Tomlox $\mathrm{C}$ is located in chloroplasts and can use both linoleic and linolenic 
acids it is the prime candidate for being the main isomer in the lipoxygenase pathway (Chen and others 2004).

As for the particular location in the tomato, the flesh was measured by breaking it into two parts: pericarp and cytosol. LOX activity was found to be greatest in the pericarp with 65-80\% occurring here (Riley and others 1996). Hatanaka and others (1992) tested the differences in LOX activity in three parts: skin with outer flesh, flesh without skin, and locular material. The locular material was found to have no activity. Whereas, $71 \%$ of the activity was in the skin with outer flesh, but when the flesh was removed from the skin the activity was drastically lower for the relatively pure skin. This suggests that LOX activity is greatest in the fleshy tissue adjacent to the skin.

\subsubsection{Hydroperoxide Lyase (HPL)}

Hydroperoxide Lyase (HPL) is a heme b protein with a molecular weight between $200-250 \mathrm{kDa}$ that is thought to be a tetramer of $62 \mathrm{kDa}$ (Zhuang and others 1998). It is most effective at a $\mathrm{pH}$ range of 5.5 to 8.0. Its location corresponds with that of lipoxygenase which is in chloroplasts and non-chloroplastic particles. It can be found in both soluble and membrane-bound forms (Yilmaz 2001a). HPL activity in tomato flesh is almost completely in the pericarp (Riley and others 1996). When Hatanaka and others (1992) measured HPL activity they looked at three parts: skin with outer flesh, flesh without skin and locular material. HPL activity was found to be distributed evenly through all three parts of the tomato. There are three kinds of HPLs: (1) 9hydroperoxide specific which produces C9 aldehydes and oxoacids; (2) 13-hydoperoxide specific which creates C6 aldehydes and C12 oxoacid; (3) nonspecific that acts on both 
substrates (Yilmaz 2001a). Hatanaka and others (1992) reported that tomato HPL utilized $85 \%$ of 13 -hydroperoxide substrate over a $10 \mathrm{~min}$ period compared to only $7.1 \%$ of 9-hydroperoxide.

\subsubsection{Alcohol Dehydrogenase $(A D H)$}

Alcohol dehydrogenase (ADH) is a dimer with a molecular mass of 90-100 kDa and contains on average 15-48 zinc atoms per enzyme dimer (Yilmaz 2001a). ADH is a nonspecific oxidoreductase capable of using the primary formed volatile alcohols or aldehydes as substrates (Stone and others 1975). ADH is the enzyme that catalyzes the interconversion of (E)-2-hexenal and (E)-2-hexenol, as well as $(E)$-2-hexenal, hexanal and hexanal (Longhurst and others 1990). There are two ADH genes: Adh1 is common in developing seed and pollen whereas Adh2 is in a range of tissues in ripening tomatoes in response to stress. Longhurst and others (1990) found that ADH activity is induced by a change in cytoplasmic $\mathrm{pH}$ that us accompanied by changes in cytoplasmic ion concentrations. They also found that $\mathrm{ADH}$ activity is present before ripening then decreases until it increases again during the postclimacteric period.

\subsection{Flavor}

\subsubsection{Tomato Volatiles}

Flavor is the critical quality characteristic in acceptance of fresh tomatoes and due to this fact consumers are willing to pay a premium for full-flavored fruit (Baldwin and others 2000). The flavor of tomatoes has been extensively studied and there have been over 400 volatiles identified in tomato (Petro-Turza 1987). Of these 400 volatiles, only 
29 have been found to be present in concentrations greater than $1 \mathrm{ppb}$. The log order units were quantified and 16 volatiles have a positive value which makes them likely to contribute to the characteristic tomato flavor. The 16 volatiles are (Z)-3-hexenal, $\beta$ ionone, hexanal, $\beta$-damascenone, 1-penten-3-one, 3-methylbutanal, (E)-2-hexanal, 2isobutylthiazole, 1-nitro-2-phenylethane, (E)-2-heptanal, phenylacetaldehyde, 6-methyl5-hepten-2-one, (Z)-3-hexanol, 2-phenylethanol, 3-methylbutanol, and methyl salicylate. However, the compounds with negative odor units may still play a role in the overall flavor (Buttery 1993). Buttery (1993) also found that by combining (Z)-3-hexenal, (Z)-3hexenol, hexanal, 1-penten-3-one, 3-methylbutanal, (E)-2-hexenal, 6-methyl-5-hepten-2one, methyl salicylate, 2-isobutylthiazole, and $\beta$-ionone at varying concentrations produces the aroma of a fresh, ripe tomato.

The volatile precursors in tomatoes include lipids, amino acids, carotenoids, terpenoids, lignin, and glycosides (Buttery and Ling 1993b, Williams 1993). The green, fresh volatiles characteristic of tomato come from the breakdown of lipids in the lipoxygenase pathway, more specifically linoleic and linolenic acids (Galliard and others 1977). Many of the volatiles found in tomatoes are developed during the blending of the product and result from the enzymatic and chemical reactions that occur. The blending allows for the enzymes and their substrates to be mixed as well as the addition of air. Lipid oxidizing enzymes react with fatty acids to create hydroperoxides that break down into carbonyl compounds. The latter can be further converted to the corresponding alcohols by alcohol dehydrogenase (Kazeniac and Hall 1970). A variety of compounds have been found in peas that originated from the enzymatic oxidation of lipids, including 
acetaldehyde, 2-butenal, 2-pentenal, 2-hexenal, 2-heptenal, 2-octenal, 2-nonenal, 2,4heptadienal and acetone (Kazeniac and Hall 1970). Alcohol dehydrogenase was found to be important to the aldehyde-alcohol ratio because it reduces the aldehydes to their alcohol counterparts, namely for acetaldehyde, 3-methylbutanal and hexenal (Kazeniac and Hall 1970). The formation of volatiles from the lipoxygenase pathway form in sequential reactions, therefore it takes different times for each volatile to reach their maximum concentration. Due to the enzymes generating new volatiles it took several minutes to reach their maximum concentrations, compared to within one minute for the volatiles not formed through enzymatic activity, that just equilibrate into the headspace (Xu and Barringer 2010a).

To find what volatiles are present prior to macerations, samples are blended with a saturated $\mathrm{CaCl}_{2}$ solution or heated in a microwave to deactivate enzymes. This assumes that the enzymes were properly deactivated and that no enzymatic activity occurred prior to the $\mathrm{CaCl}_{2}$ penetrating the entire sample (Buttery and Ling 1993b). The volatiles that showed no significant change due to tissue disruption are 3-methylbutanal, pentanol, (Z)3-hexenol, hexanal, 6-methyl-5-hepten-2-one, phenylacetaldehyde and 2-phenylethanol. The volatiles that showed no change are not enzymatically formed through the lipoxygenase pathway. (E)-2-pentenal was the only one to appear after disruption, which means it was most likely formed solely through the lipoxygenase pathway. The volatiles that increase after tissue disruption include (Z)-3-hexenal, $(E)$-2-hexenal, hexanal, $(E)$-2-heptenal, 1-penten-3-one, 1-penten-3-ol, geranylacetone, 2- 
isobutylthiazole and 1-nitro-2-phenylethane. These volatiles are from the lipoxygenase pathway (Buttery and Ling 1993b).

Two other volatiles in tomatoes are furfural and methanol. Higher amounts of each were found in over-ripe tomatoes which is consistent with high degrees of demethylation and furfural formation. Methanol is produced from pectins by the depolymerization and demethylation by pectic enzymes. The resulting uronic acids and ascorbic acid would be the most likely precursors for furfural (Kazeniac and Hall 1970).

The maturity stage of tomatoes has been found to be very important in the amounts of (E)-2-hexenal and (Z)-3-hexenal produced with the highest levels in the red mature stage. This may be due to the variation of lipids, lipases and lipoxygenase throughout maturation. They were found to reach the highest amounts at the climacteric stage in apples (Rhodes and Wooltorton 1967). The total lipids were found to vary with fruit maturity at harvest as well as depending on the variety and storage conditions (Kazeniac and Hall 1970). The enzymes appeared to be at least one of the limiting factors in the concentration of (Z)-3-hexenal in green tomatoes (Kazeniac and Hall 1970).

Buttery and others (1988) analyzed a tomato broken down into four parts: pulp, fluid, seeds and skin. The fluid is the locular fluid which was obtained by filtering the fluid through a stainless steel screen to remove the seeds. None of the portions are able to be separated from one another without damaging the fresh condition, but volatile tests were conducted within 5 min to minimize changes in volatile release. The pulp make up about $70 \%$ of the tomato, yet contains similar volatile levels to the whole tomato with the exception of (E)-2-hexenal and C6 alcohols which it contained higher concentrations of. 
The fluid was about $20 \%$ of the tomato. (Z)-3-Hexenal, (E)-2-hexenal and 1-penten-3one concentrations in the fluid were about half of that found in the entire tomato. The seeds made up a miniscule $0.3 \%$ of the tomato and had 100 times lower levels of most volatiles compared to the whole tomato except $(E)$-2-hexenal which was the same. The seeds make up such a small amount that it is unlikely that they contribute significantly to the flavor. The skin made up $10 \%$ of the whole tomato. However, it contained considerably higher levels of C6 aldehydes and several-fold higher concentrations of C6 alcohols than in the whole tomato or in the interior pulp. It must be noted that this could be partially due to the tissue damage during peeling. Buttery and others (1988) also studied 10 different lines of tomatoes and found no marked differences in concentrations of C5-C13 volatiles, although no thorough statistical analysis was done. Xu and Barringer (2010a) found that grape tomato had higher levels of volatiles than vineripened, cherry and roma tomatoes. It was also reported that the formation of a mixture of (Z)-3-hexenal and (E)-2-hexenal during chewing is greater in cherry tomato than plum and delice tomatoes (Brauss and others 1998). Nonanal levels were also found to be greater in tomatillo, cherry tomato and grape tomato than in roma and vine-ripened tomatoes (Xu and Barringer 2010b).

\subsection{2 (Z)-3-Hexenal}

(Z)-3-Hexenal is the key contributor to the characteristic green flavor of tomato. (Z)-3-Hexenal is formed through the lipoxygenase pathway by hydroperoxide lyase where its precursor lipid is linolenic acid. It is present in tomatoes at the highest concentration (12,000 ppb) and has the highest odor log unit (3.7) of the 30 volatiles 
present at greater than $1 \mathrm{ppb}$ (Buttery 1993). (Z)-3-Hexenal concentration in macerated tomato increases rapidly until it reaches its maximum around $3 \mathrm{~min}$. It is gradually lost due to isomerization to $(E)$-2-hexenal, transformation to hexanal and reductase conversion to (Z)-3-hexenol (Buttery and Ling 1993b, Xu and Barringer 2009).

\subsection{3 (Z)-3-Hexenol}

(Z)-3-Hexenol is formed from the reduction of (Z)-3-hexenal by alcohol dehydrogenase. There is no significant change in concentration due to tissue disruption (Buttery and Ling 1993a). (Z)-3-hexenol has a green odor but due to its high odor threshold compared to (Z)-3-hexenal and (E)-2-hexenal it affects the flavor less (PetroTurza 1987). The (Z)-2-hexenol concentrations in tomato are typically low (Yilmaz and others 2002).

\subsubsection{Hexanal}

Hexanal is produced via the lipoxygenase pathway by reaction of linoleic acid with hydroperoxide lyase. It can also be formed through the transformation of (Z)-3hexenal, derived from linolenic acid. The conversion is only about $2 \%$ of the hexanal formation because hexanal formed from linoleic acid inhibits the formation of $(Z)$-3hexenal from linolenic acid. Therefore linoleic acid is the controlling factor in the formation of hexanal (Xu and Barringer 2009). It has a green flavor at low concentrations but at higher concentration it has a rancid vegetable fat flavor. The green flavor is much less prevalent than (Z)-3-hexenal and (E)-2-hexenal (Petro-Turza 1987). Due to hexanal being formed through enzymatic activity it took approximately 6 min to reach its maximum concentration in tomatillo and then decreased due to degradation and 
removal from sampling (Xu and Barringer 2010a). Hexanal had a greater concentration in cherry tomato and tomatillo than grape, roma and vine-ripened tomatoes ( $\mathrm{Xu}$ and Barringer 2010b). An increase in temperature from 4 to $23^{\circ} \mathrm{C}$ correlated with an increase in hexanal concentration. The increase in hexanal concentration may be due to an increase in partition coefficient including increased volatility or an increase in the amount of volatiles generated by the enzymes (Xu and Barringer 2009).

\subsubsection{1-Penten-3-one and (E)-2-Pentenal}

1-Penten-3-one and (E)-2-pentenal reached their maximum concentrations later than $(Z)$-3-hexenal, hexenal and $(E)$-2-hexenal at $35 \mathrm{~min}$ for 1-penten-3-one and $28 \mathrm{~min}$ for $(E)$-2-pentenal in tomatillo. The maximum concentrations were earlier in tomatoes than tomatillos. They are formed through branch reactions of enzymatic oxidation of linolenic acid (Xu and Barringer 2010a). Cherry tomato and grape tomato had higher concentrations of 1-penten-3-one than roma and vine-ripened tomatoes during chewing (Xu and Barringer 2010b). The concentration of 1-penten-3-one increased with increasing temperature form 4 to $37^{\circ} \mathrm{C}$ with and without enzymatic activity. 1-Penten-3one increases in the headspace after tissue disruption, and the addition of lipoxygenase and alcohol dehydrogenase in tomato homogenates decreases its concentration (Xu and Barringer 2009).

\subsubsection{3-Methylbutanal and Phenylacetaldehyde}

Tomato contains volatile nitro compounds which are not found in any other fruit or vegetable (Baldwin and others 2000). They appear in tomatoes as they ripen from breaker to mature red stages. The nitro compounds are formed by an amino acid being 
converted by an enzyme to its corresponding oxime which is then converted by another enzyme system to a mixture of the nitro compound and nitrile. The enzymes in this reaction have not been identified. Both the nitro compound and nitrile compound can be found in fresh tomato. 1-Nitro-phenylethane was found to be converted to phenylacetaldehyde by making a water solution with the nitro compound at a $\mathrm{pH}$ of 10.0 and then making it mildly acidic ( $\mathrm{pH} 4.5)$. This is referred to as the Nef reaction. This reaction occurs readily so it is believed to be mediated by an enzyme system and is most likely the cause of the formation of 3-methylbutanal and phenylacetaldehyde. The accepted pathway for these aldehydes is normally by Strecker degradation; however these samples were not heated (Buttery 1993). 3-Methylbutanal is from the enzymatic precursor amino acid leucine and has a caramel aroma (Xu and Barringer 2010a) whereas phenylacetaldehyde is enzymatically from phenylalanine and has a floral note (Buttery and others 1988).

\subsection{7 (E)-2-Hexenal}

(E)-2-Hexenal has a slightly less fresh, green aroma than (Z)-3-hexenal but its effect on the flavor is similar (Petro-Turza 1987). Isomerization of (Z)-3-hexenal creates (E)-2-hexenal, which can occur either enzymatically by Z3/E2 isomerase or nonenzymatically (Galliard and Matthew 1977). The maximum concentration of $(E)$-2hexenal is at $12 \mathrm{~min}$ in tomatillo, which is significantly later than (Z)-3-hexenal

maximum formation. The extra enzyme step causes a delay in the maximum being reached (Luning and others 1995). 


\subsubsection{6-Methyl-5-hepten-2-one}

The flavor of 6-methyl-5-hepten-2-one is debated. Kazeniac and Hall (1970) found it to have a fruity flavor but when added to tomato juice it did not enhance the tomatolike aroma. Others have found it to have a cooked or heat-treated flavor (PetroTurza 1987). It is a terpene related compound found along with acetone. 6-Methyl-5hepten-2-one and acetone have been found from lycopene degradation during the heating of tomato pulp. Lower concentrations of 6-methyl-5-hepten-2-one were found when tomatoes were blended under nitrogen rather than air (Kazeniac and Hall 1970). A high lycopene tomato was compared to other varieties of vine ripened tomatoes and found to contain similar concentrations of suspected lycopene degradation products 6-methyl-5hepten-2-one, 6-methyl-5-hepten-2-ol and geranylacetone.

\subsubsection{Methyl Salicylate}

Methyl salicylate is a lignin related compound that is incredibly variable in the concentrations present in tomato. The variability has yet to be linked with any difference in tomato lines, maturity or growing conditions (Buttery and Ling 1993b). Other lignin related compounds identified in tomato include eugenol, and guaiacol. These two were found in similar amounts to methyl salicylate and varied by variety as well (Kazeniac and Hall 1970).

\subsubsection{2-Isobutylthiazole}

Alkylthiazoles are commonly found in cooked products but tomato is one of the few raw foods to contain them. 2-Isobutylthiazole is the only alkylthiazole found in tomatoes. It is believed to develop from leucine. Leucine is first broken down into 3- 
methylbutanal which then condenses with cystamine to give a thiazolidine. The thiazolidine oxidizes enzymatically to the thiazole (Buttery and Ling 1993b). 2Isobutylthiazole has a spoiled vinelike and slightly horseradish flavor but when added to tomato improves the flavor by decreasing the harsh, unpleasant notes and intensifies the flavor (Petro-Turza 1987). The amounts of 2-isobutylthiazole are not dependent on the crushing procedure or presence of oxygen, therefore the majority of it should be present in the intact fruit. However, the concentrations vary from one variety of tomato to another (Kazeniac and Hall 1970).

\subsubsection{1 $\beta$-Ionone}

$\beta$-Ionone is present in tomato at the lowest concentration but due to its low odor threshold it has one of the highest log odor units (2.8) (Buttery 1993). $\beta$-Ionone is a carotenoid related volatile, along with 6-methyl-5-hepten-2-one. It is formed via an oxidative mechanism (Buttery and Ling 1993b). The decomposition of $\beta$-carotene is the

proposed method of formation (Kazeniac and Hall 1970). A high $\beta$-carotene tomato was studied and it contained high levels of $\beta$-ionone and $\beta$-cyclocitral compared to regular vine-ripened tomato varieties (Buttery and others 1988).

\subsubsection{Effect of Fatty Acid on Flavor}

Lipids and fatty acids are precursors to the aldehydes (Z)-3-hexenal, $(E)$-2hexenal, and hexanal, the alcohols ( $Z$ )-3-hexenol and 1-hexanol and the ketone 1-penten3-one (Baldwin and others 2000). Due to the variation of fatty acid composition in tomatoes researchers have looked at the effects of adding linoleic and linolenic acids to tomato homogenates. The addition of linoleic acid was found to increase the levels of 
hexanal and 1-hexanol whereas the addition of linolenic acid enhanced the production of (Z)-3-hexenal, (E)-2-hexenal and (Z)-3-hexenol (Boukobza and others 2001, Chen and others 2004, Riley and Thompson 1998). In green bell pepper, with the addition of linoleic acid there was a significant increase in the levels of hexanal, hexanal, 2pentylfuran, (E)-2-heptenal, (E)-2-octenal, (E)-2-nonenal and (Z)-3-hexenal (Luning and others 1995). Instead of adding fatty acids, there are tomato cultivars that are bred to contain different levels of linoleic and linolenic acids. When the ratio of linoleic acid to linolenic acid is greater there was a significant increase in the hexanal to hexenal ratio (Gray and others 1999). Similar findings were found when the expression of a yeast $\Delta-9$ desaturase gene was altered to produce higher concentrations of palmitoleic acid, oleic acid, linoleic acid, as well as total fatty acid concentration. Hexanal and 1-hexanol, believed to be derived from oleic and linoleic acids, were more than two times greater than the wild type (Wang and others 1996). By altering the Spr2 gene higher levels of linoleic acid were created and lower levels of linolenic acid formed. This modification from the wild type caused an increase in hexanal and a decrease in ( $Z$ )-3-hexenal (Canoles and others 2006).

\subsubsection{Effect of Lipoxygenase on Flavor}

A mutant tomato line was bred to contain higher levels of linoleic levels and lower levels of linolenic acid. With this change in fatty acid content the linolenic derived (Z)-3-hexenal content increased while the linoleic acid derived hexanal did not. This change in volatile concentration is most likely not related to lipoxygenase since it has no specificity for linoleic or linolenic acids. Hydroperoxide lyase is most likely the enzyme 
involved due to its higher affinity for linolenic acid (Canoles and others 2006). Tomatoes naturally containing varying concentrations of lipoxygenase, hydroperoxide lyase and alcohol dehydrogenase were found to have no significant correlation with hexanal, (Z)-3hexenal, $(E)$-2-hexenal, $(E)$-2-heptenal, pentenone, and (Z)-3-hexenol (Yilmaz and others 2001). Similar results were found when the control group had consistently higher concentrations of all volatile compounds than any enzyme treatment. There was a steady decrease in the concentrations of hexanal, $(Z)$-3-hexenal, $(E)$-2-hexenal, and 1-penten-3one with the lipoxygenase, alcohol dehydrogenase and lipoxygenase/alcohol dehydrogenase treatments in red tomatoes (Yilmaz and others 2002). Interestingly, when exogenous linoleic and linolenic acid is added to tomato homogenates made from tomatoes with low Tomlox C mRNA compared to wild type the increases in hexanal and hexenal levels were much lower than in the wild type controls (Chen and others 2004).

\subsubsection{Effect of Storage on Flavor}

Studies have shown that low storage temperatures (below $13^{\circ} \mathrm{C}$ ) can cause poor tomato fruit quality, as well as chill damage (Hardenburg and others 1986). However, red-ripe fruit has been found to withstand low temperature storage for longer periods of time without chilling injury (Cook and others 1958). Ripe tomatoes stored at $5^{\circ} \mathrm{C}$ for 6

days had a significant decrease in volatiles and the main contributor being (Z)-3-hexenal (Stern and others 1994). After 2-12 days of storage at $5^{\circ} \mathrm{C}$ had markedly lower ripe aroma than those stored at 12.5 and $20^{\circ} \mathrm{C}$. Hexanal, 2+3-methylbutanol, (E)-2-heptenal, and 2-isobutylthiazole were present in lower concentrations (Maul and others 2000). 


\subsection{Analytical Methods for Headspace Analysis}

Identification and quantification of tomato volatile compounds has been done by a variety of methods. Most methods require that the volatile compounds be extracted and/or concentrated prior to analysis. Common extraction methods include static headspace, steam distillation, solvent extraction, solid-phase microextraction (SPME), and purge-and-trap (Beltran and others 2006, Buttery and others 1971). SPME is commonly used because it is a rapid solvent free method and costs less compared to other extraction methods (Beltran and others 2006). A common method of tomato volatile quantification is using gas chromatography-mass spectrometry (GC-MS) which can be paired with most extraction methods (Petro-Turza 1987). Gas chromatography separates extracted volatiles based on each volatile's different retention times in a separation column. The gas chromatography elutates were then ionized for detection by mass spectrometry (Beltran and others 2006). A negative for GC-MS is that the sample preparation required makes it difficult to do real-time analysis of volatiles, as well as being able to follow the dynamics of the reaction. The time it takes to prepare the samples can be decreased by trapping volatiles on some form of trapping material, but this is an indirect measure of volatiles which is not favored (Boukobza and others 2001).

Atmospheric pressure ionization mass spectrometry (API-MS) is another method for identification and quantification of volatile compounds. API-MS can measure mixtures of volatiles with a millisecond delay and concentrations as low as $10 \mathrm{ppb}$ (Boukobza and others 2001). API-MS methods require the volatiles emitted by foods to be collected prior to running the sample (Spanel and Smith 1999). Another method that 
is able to measure volatile compounds is proton transfer reaction mass spectrometry (PTR-MS). PTR-MS is a chemical ionization based mass spectrometry that can measure real-time release of volatiles at concentrations as low as $1 \mathrm{ppb}$ (Hansel and others 1995). API-MS and PTR-MS are both capable of doing real-time analysis but their major fault is in their ability to distinguish between isomers like (Z)-3-hexenal and (E)-2-hexenal, both of which are critical in tomato's flavor profile (Xu and Barringer 2009).

\subsection{Selected Ion Flow Tube Mass Spectrometry (SIFT-MS)}

\subsubsection{Principles of SIFT-MS}

Selected Ion Flow Tube-Mass Spectrometry (SIFT-MS) is a mass spectrometry technique used for real-time analysis that utilizes chemical ionization of sample trace gases by selected ions during a defined amount of time along a flow tube. It is used due to its ability to quantify volatile compounds in real time while distinguishing between key isomers in the headspace above tomato and does not require sample preparation (Xu and Barringer 2009).

The principle of SIFT-MS can be explained by Figure 2.2. Initially, precursor ions are generated by microwave gas discharge into an upstream chamber where a quadrupole mass filter selects only the reagent ions, $\mathrm{H}_{3} \mathrm{O}^{+}, \mathrm{NO}^{+}$, and $\mathrm{O}_{2}{ }^{+}$. These ions were selected based on their ability to not react with the major components of air $\left(\mathrm{N}_{2}, \mathrm{O}_{2}\right.$, $\mathrm{H}_{2} \mathrm{O}, \mathrm{Ar}$, and $\mathrm{CO}_{2}$ ) but react with the sample volatile compounds and many inorganic molecules (Spanel and Smith 1999). Following the upstream chamber, the ions go through a Venturi inlet into an inert carrier gas, helium and argon, flowing along a flow tube at a known velocity. The sample gas enters at a controlled rate into the flow tube to 
react with the precursor ions to produce product ions. The count rates of the precursor and product ions are determined using second quadrupole mass filter. Lastly, a particle multiplier detects the ions at the selected masses and the count rate which is used to calculate the concentration of each selected volatile.

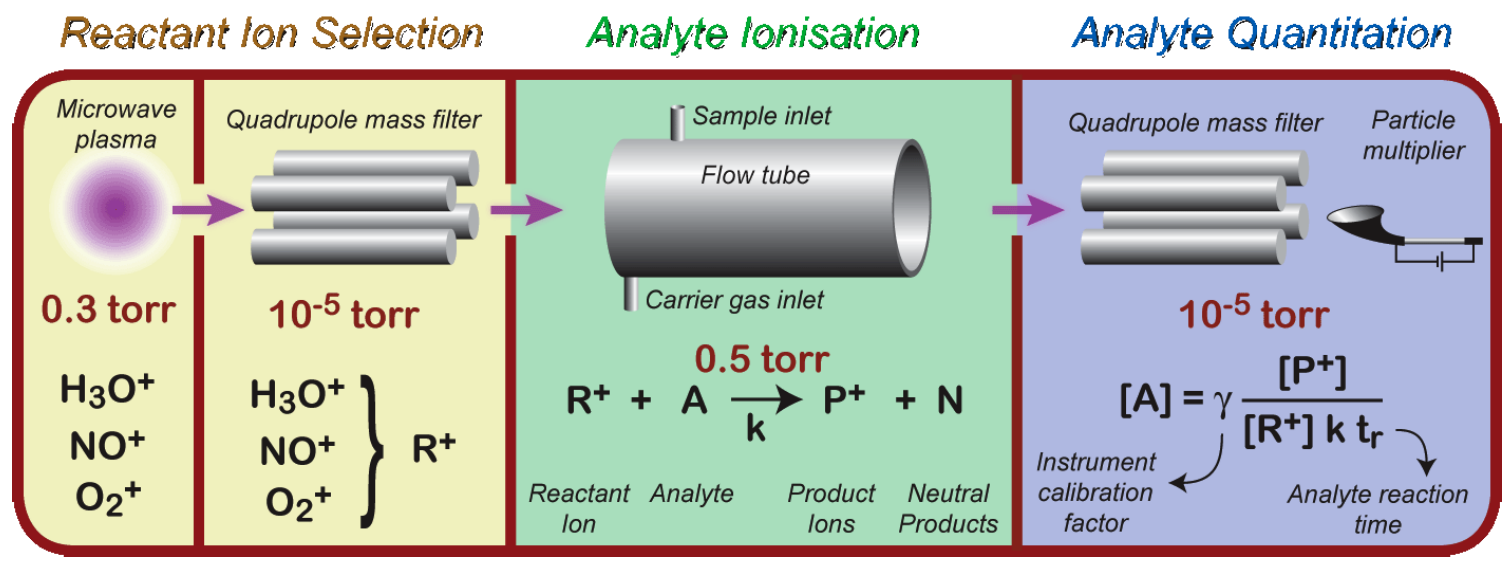

Figure 2.2 Principles of Selected Ion Flow Tube Mass Spectrometry

SIFT-MS has been used for years to identify the kinetic data for a large number of ion-neutral reactions (Adams and Smith 1976). The kinetic data obtained includes the rate coefficient $(\mathrm{k})$, the product ions and their relative amounts, which is all stored in the SIFT database library (Spanel and Smith 1999). Thus, the concentrations of individual compounds (M) in a sample can be instantly quantified from the ratio of the product to precursor ion count rates $\left(\mathrm{I}_{\mathrm{p}} / \mathrm{I}\right)$ using Equation 1:

$$
[M]=\frac{I_{p}}{I k t}
$$

The reaction time (t) can be defined by the known flow velocity of the helium carrier gas and the length of the flow tube (Spanel and Smith 1999). 
SIFT-MS provides rapid identification and quantification of volatiles in a wide range of sampling methods. It does so by using soft chemical ionization which results in less compound fragmentation and a simpler mass spectrum when compared to electron impact ionization used in GC-MS. Another benefit to SIFT-MS is that it utilizes multiple reagent ions $\left(\mathrm{H}_{3} \mathrm{O}^{+}, \mathrm{O}_{2}{ }^{+}\right.$and $\left.\mathrm{NO}^{+}\right)$to chemically ionize volatiles instead of only one ion used in PTR-MS, making the identification of isomers easier since there are one or two product ions from each volatile compound. The sensitivity of this method is dependent on the time allowed for collecting data. A compound can be identified in a few seconds if it is present at greater than $10 \mathrm{ppb}$ but a level as low as $0.1 \mathrm{ppb}$ takes closer to 10 seconds (Spanel and Smith 1999).

\subsubsection{Full Scan vs. MIM Scan}

SIFT-MS can be run in two different modes: Full Scan and Multiple Ion Monitoring mode (MIM). Full Scan is used when sample's volatile concentrations do not vary over time. The air mixture will flow at a known rate into the carrier gas and the spectrum of precursor and product ions are found through the downstream quadrupole ion sweeping over a selected mass-charge ratio $(\mathrm{m} / \mathrm{z})$ range. MIM is used to identify volatile compounds in a sample which the concentrations of volatiles vary over time. In this mode the downstream mass spectrometer rapidly switches between the masses of the precursor ions and the chosen product ions and dwelling on each mass for a predetermined short time interval. Quick sampling is possible because of the fast flow rate of the carrier gas along the flow tube and the sample gas along the inlet tube. The response time is approximately $20 \mathrm{~ms}$ (Smith and Spanel 2005). 


\subsubsection{Ion Chemistry}

SIFT-MS works on the understanding that when each trace gas, M, reacts with chosen precursor ions, and the goal is that the product ion will be unambiguously identified. Past experiments have studied the reactions of the precursor ions with a wide array of classes of compounds including alcohols, aldehydes, ketones, carboxylic acids, esters and ethers (Spanel and Smith 1999). These reactions have been compiled to create a SYFT library containing more than 500 volatile compounds. Depending on the analyte and reagent ion, five types of reactions can occur (Harper and others 2010).

(1) Proton transfer $\left(\mathrm{H}^{+}\right)$:

$$
\mathrm{H}_{3} \mathrm{O}^{+}+\mathrm{M} \rightarrow \mathrm{MH}^{+}+\mathrm{H}_{2} \mathrm{O}
$$

The majority of reactions with $\mathrm{H}_{3} \mathrm{O}^{+}$proceed by rapid proton transfer producing $\mathrm{MH}^{+}$ions because the sample volatile has a greater proton affinity than $\mathrm{H}_{2} \mathrm{O}$ (Spanel and Smith 1999). Proton transfer is an exothermic reaction that normally results in one or two product ions. Sometimes the $\mathrm{MH}^{+}$ions will dissociate into $[\mathrm{M}-\mathrm{OH}]^{+}$eliminating an $\mathrm{H}_{2} \mathrm{O}$. This most often happens after the protonation of some alcohols, aldehydes and carboxylic acids (Smith and Spanel 2005).

(2) Charge transfer:

$$
\begin{aligned}
& \mathrm{O}_{2}^{+}+\mathrm{M} \rightarrow \mathrm{M}^{+}+\mathrm{O}_{2} \\
& \mathrm{NO}^{+}+\mathrm{M} \rightarrow \mathrm{M}^{+}+\mathrm{NO}
\end{aligned}
$$

For the charge transfer reaction to proceed the ionization energy (IE) of M must be less than the IE of NO $(9.26 \mathrm{eV})$ and $\mathrm{O}_{2}(12.06 \mathrm{eV})($ Smith and Spanel 2005). The IE of $\mathrm{O}_{2}$ is higher than most organic molecules, making it a valuable precursor for many 
volatiles. NO has a lower IE than $\mathrm{O} 2$, therefore the reactions with $\mathrm{NO}$ usually involve aromatic hydrocarbons, low molecular weight alkanes and organosulfur compounds (Spanel and Smith 1999).

(3) Dissociative charge transfer:

$$
\mathrm{O}_{2}^{+}+\mathrm{M} \rightarrow \text { Fragment }^{+}+\text {Neutral fragments }+\mathrm{O}_{2}
$$

This reaction involves a charge transfer as well as the formation of fragments of the original compound. It frequently involves $\mathrm{O}_{2}{ }^{+}$instead of $\mathrm{NO}^{+}$because of the greater IE of $\mathrm{O}_{2}^{+}$(Smith and others 2003a).

(4) Association:

$$
\begin{array}{lll}
\mathrm{NO}^{+}+\text {Analyte }+\mathrm{M} & \rightarrow & \text { Analyte. } \mathrm{NO}^{+}+\mathrm{M} \\
\mathrm{H}_{3} \mathrm{O}^{+}+\text {Analyte }+\mathrm{M} & \rightarrow & \text { Analyte. } \mathrm{H}_{3} \mathrm{O}^{+}+\mathrm{M}
\end{array}
$$

Association reactions are very common between NO+ and some types of polar organic compounds including carboxylic acids, esters and ketones. It becomes the most efficient when the IE(M) is not much different than IE(NO). The stabilizing agent for association reactions tends to be the helium carrier gas. Association reactions commonly occur in parallel with some form of a charge transfer (Smith and Spanel 2005).

(5) Hydride extraction:

$$
\mathrm{NO}^{+}+\mathrm{M} \rightarrow[\mathrm{M}-\mathrm{H}]^{+}+\mathrm{HNO}
$$

Hydride extraction involves the transfer of a hydride atom to the analyte which most commonly results in a single product ion and an HNO molecule. This reaction is the main one between $\mathrm{NO}^{+}$with aldehydes and ethers (Smith and Spanel 2005). 


\subsubsection{Validation of SIFT-MS}

Unlike a GC-MS, SIFT-MS does not require a known concentration of a reference substance to validate itself. SIFT-MS is able to do an automatic, on-line validation completed by using a dilute gas mixture of benzene, ethylbenzene, toluene, m-xylene, oxylene, and p-xylene. The validation process takes approximately $15 \mathrm{~min}$. The validation process requires the SIFT-MS identify the rate constants and product ratios for the above gas samples (Smith and Spanel 2005).

\subsubsection{Application of SIFT-MS in Food Science}

SIFT-MS has been used on a multitude of applications in a variety of fields including environmental science, microbiological studies, clinical science, and food science. Non-food science studies include the analysis of breath volatile compounds for medical diagnosis and therapeutic monitoring (Senthilmohan and others 2000), detection of volatiles produced by microbial growth in urine (Storer and others 2011), and analysis of diesel engine exhaust (Smith and others 2004).

SIFT-MS is advantageous for studying food because it utilizes three precursor ions which allow it to distinguish between isomers (Smith and Spanel 2005). One of the major applications of SIFT-MS in the food industry is with fruits and vegetables. In other studies, the SIFT-MS has been used for the real-time analysis of tomato volatile release during chewing (Xu and Barringer 2010b), the effect of temperature on the lipidrelated volatiles (Xu and Barringer 2009), as well as the comparison of tomato volatiles with those of tomatillo (Xu and Barringer 2010a). Other types of food that SIFT-MS has been used to analyze include swiss cheese (Harper and others 2010), cocoa (Huang and 
Barringer 2010), and determining the olive oil oxidative status (Davis and McEwan 2007). 


\section{Chapter 3: Materials and Methods}

Ten varieties of tomatoes were either purchased from supermarkets in Columbus, Ohio, USA (7 varieties) or grown in Fremont, OH (3 varieties). Red mature tomatoes of uniform size were used. Five replicates were run due to the large variation from tomato to tomato. Each replicate contained multiple tomatoes to reach sample weights. Tomatoes were washed and stored at room temperature for a minimum of $5 \mathrm{~h}$ prior to testing. Tests were carried out at $20-23^{\circ} \mathrm{C}$. Tomatoes were peeled whole using a paring knife and cutting as close to the peel as possible. Peel and flesh samples were analyzed separately.

\subsection{Headspace Volatile Quantification}

\subsubsection{Sample Preparation}

Each replicate contained multiple tomatoes to reach $37.50 \mathrm{~g}$ samples. In the chopper (Magic Bullet short cup, Homeland Housewares LLC, Sherman Oaks, CA, USA) $37.50 \mathrm{~g}$ of tomato flesh or peel was blended with $12.50 \mathrm{~g}$ water and $1.88 \mathrm{~g} \mathrm{NaCl}$ for $30 \mathrm{sec} . \mathrm{NaCl}$ (Extra Fine 325 Salt, Morton Salt Inc., Chicago, IL, USA) was added to increase the amount of volatiles in the headspace. Nonvolatile solutes are added to 
increase the partial pressures of the volatile compounds therefore increasing the concentration of volatile compounds in the vapor phase (Poll and Flink 1984).

\subsubsection{SIFT-MS}

The headspace volatile compounds were analyzed using a selected ion flow tubemass spectrometer (SIFT-MS) (SYFT Voice100, Syft Ltd., Christchurch, New Zealand) using the method described by Xu and Barringer (2009). All samples were run using selected ion mode (SIM) scans. The concentration of each compound was found based on pre-determined reaction kinetics (Table 3.1). The absolute concentration of each volatile was calculated by taking into account the pre-determined reaction rate for the volatile with that precursor ion and the dilution of the sample gas into the carrier gas (Smith and Spanel 1996). Some volatiles are not reported due to low concentrations or conflicts.

Samples were measured by piercing a polytetrafluroethylene faced silicone septum glued to the cap of a $300 \mathrm{~mL}$ chopper with a short 14-gauge passivated needle. The needle point was approximately $6 \mathrm{~cm}$ above the sample. A long 14-gauge syringe needle was $1 \mathrm{~cm}$ above the sample to maintain the pressure in the bottle at atmosphere pressure and to provide oxygen for lipid oxidation. Immediately following chopping, the cap with septum was placed on the small cup and samples were run for $180 \mathrm{sec}$ on the SIFT-MS. Samples were run at $20-23^{\circ} \mathrm{C}$. Inlet and outlet temperatures were set at $120^{\circ} \mathrm{C}$. Validations were run prior to scanning the samples. The validations involve measuring the exact amount of the gas mixtures benzene, ethylbenzene, toluene, mxylene, $o-x y l e n e$ and p-xylene and comparing the measured concentrations to the actual 
concentrations to ensure the machine is calibrated correctly. Air samples were run between tests to remove any potential contaminants present during preparation.

Table 3.1 Reaction kinetics of the selected volatile compounds measured in the headspace of tomato

\begin{tabular}{|c|c|c|c|c|c|}
\hline Compound & $\begin{array}{l}\text { Precursor } \\
\text { Ion }\end{array}$ & $\begin{array}{l}\mathrm{k}\left(10^{-9}\right. \\
\left.\mathrm{cm}^{3} / \mathrm{s}\right)\end{array}$ & $m / z$ & Product Ion & Reference \\
\hline (E)-2-heptenal & $\mathrm{NO}^{+}$ & 3.9 & 111 & $\mathrm{C}_{7} \mathrm{H}_{11} \mathrm{O}^{+}$ & Spanel and others 2002 \\
\hline (E)-2-hexenal & $\mathrm{NO}^{+}$ & 3.8 & 71 & $\mathrm{C}_{4} \mathrm{H}_{7} \mathrm{O}^{+}$ & Spanel and others 1997 \\
\hline (Z)-3-hexenal & $\mathrm{H}_{3} \mathrm{O}^{+}$ & 4.2 & 81 & $\mathrm{C}_{6} \mathrm{H}_{9}^{+}$ & Spanel and others 1997 \\
\hline 1-butanol & $\mathrm{NO}^{+}$ & 2.2 & 73 & $\mathrm{C}_{4} \mathrm{H}_{9} \mathrm{O}^{+}$ & Spanel and Smith 1997 \\
\hline 1-hexanol & $\mathrm{NO}^{+}$ & 2.4 & 101 & $\mathrm{C}_{6} \mathrm{H}_{13} \mathrm{O}^{+}$ & Spanel and others 1997 \\
\hline 1-penten-3-one & $\mathrm{NO}^{+}$ & 2.5 & 114 & $\mathrm{C}_{5} \mathrm{H}_{8} \mathrm{O}^{+} . \mathrm{NO}^{+}$ & Syft Technologies 2009 \\
\hline 1-propanol & $\mathrm{NO}^{+}$ & 2.3 & 59 & $\mathrm{C}_{3} \mathrm{H}_{7} \mathrm{O}^{+}$ & Spanel and Smith 1997 \\
\hline 2,3-butanediol & $\mathrm{NO}^{+}$ & 2.3 & $89+107$ & $\mathrm{C}_{4} \mathrm{H}_{9} \mathrm{O}_{2}^{+}, \mathrm{C}_{4} \mathrm{H}_{9} \mathrm{O}_{2}^{+} \cdot \mathrm{H}_{2} \mathrm{O}$ & Syft Technologies 2009 \\
\hline 2,3-butanedione & $\mathrm{NO}^{+}$ & 1.3 & 86 & $\mathrm{C}_{4} \mathrm{H}_{6} \mathrm{O}_{2}{ }^{+}$ & Spanel and others 1997 \\
\hline 2-isobutylthiazole & $\mathrm{H}_{3} \mathrm{O}^{+}$ & 3 & 142 & $\mathrm{C}_{7} \mathrm{H}_{11} \mathrm{NS} . \mathrm{H}^{+}$ & Syft Technologies 2009 \\
\hline 2-methylpropanal & $\mathrm{O}_{2}^{+}$ & 3 & 72 & $\mathrm{C}_{4} \mathrm{H}_{8} \mathrm{O}^{+}$ & Spanel and others 2002 \\
\hline 2-pentanol & $\mathrm{NO}^{+}$ & 2.5 & 87 & $\mathrm{C}_{5} \mathrm{H}_{11} \mathrm{O}^{+}$ & Syft Technologies 2009 \\
\hline 2-pentanone & $\mathrm{NO}^{+}$ & 3.1 & 116 & $\mathrm{NO}^{+} . \mathrm{C}_{5} \mathrm{H}_{10} \mathrm{O}$ & Spanel and others 1997 \\
\hline 2-pentenal* & $\mathrm{NO}^{+}$ & 4.0 & 83 & $\mathrm{C}_{5} \mathrm{H}_{7} \mathrm{O}^{+}$ & Spanel and others 2002 \\
\hline 3-methylbutanal & $\mathrm{NO}^{+}$ & 3.0 & 85 & $\mathrm{C}_{5} \mathrm{H}_{9} \mathrm{O}^{+}$ & Spanel and others 2002 \\
\hline $\begin{array}{l}\text { 6-methyl-5-hepten-2- } \\
\text { one }\end{array}$ & $\mathrm{H}_{3} \mathrm{O}^{+}$ & 3.0 & 109 & $\mathrm{C}_{8} \mathrm{H}_{13}^{+}$ & Syft Technologies 2009 \\
\hline acetaldehyde & $\mathrm{NO}^{+}$ & 6.0 & $\begin{array}{c}43+61+ \\
79\end{array}$ & $\begin{array}{c}\mathrm{CH}_{3} \mathrm{CO}^{+}, \mathrm{CH}_{3} \mathrm{CO}^{+} . \mathrm{H}_{2} \mathrm{O} \\
\mathrm{CH}_{3} \mathrm{CO}^{+} .2 \mathrm{H}_{2} \mathrm{O}\end{array}$ & Spanel and others 1997 \\
\hline
\end{tabular}

Continued 
Table 3.1 Continued

\begin{tabular}{|c|c|c|c|c|c|}
\hline acetone & $\mathrm{NO}^{+}$ & 1.2 & 88 & $\mathrm{C}_{3} \mathrm{H}_{6} \mathrm{O} . \mathrm{NO}^{+}$ & Spanel and others 1997 \\
\hline benzaldehyde & $\mathrm{O}_{2}^{+}$ & 2.4 & 106 & $\mathrm{C}_{7} \mathrm{H}_{6} \mathrm{O}^{+}$ & Spanel and Smith 1997 \\
\hline benzyl alcohol & $\mathrm{NO}^{+}$ & 2.3 & 108 & $\mathrm{C}_{7} \mathrm{H}_{8} \mathrm{O}^{+}$ & Wang and others 2004 \\
\hline cyclic terpenes** & $\mathrm{NO}^{+}$ & 2.3 & 136 & $\mathrm{C}_{10} \mathrm{H}_{16}^{+}$ & Syft Technologies 2009 \\
\hline dimethyl disulfide & $\mathrm{H}_{3} \mathrm{O}^{+}$ & 2.6 & 95 & $\left(\mathrm{CH}_{3}\right)_{2} \mathrm{~S}_{2} \cdot \mathrm{H}^{+}$ & Spanel and Smith 1998a \\
\hline dimethyl sulfide & $\mathrm{O}_{2}^{+}$ & 2.2 & 62 & $\left(\mathrm{CH}_{3}\right)_{2} \mathrm{~S}^{+}$ & Spanel and Smith 1998a \\
\hline ethanol & $\mathrm{NO}^{+}$ & 1.2 & $\begin{array}{c}45+63+ \\
81\end{array}$ & $\begin{array}{c}\mathrm{C}_{2} \mathrm{H}_{5} \mathrm{O}^{+}, \mathrm{C}_{2} \mathrm{H}_{5} \mathrm{O}^{+} . \mathrm{H}_{2} \mathrm{O} \\
\mathrm{C}_{2} \mathrm{H}_{5} \mathrm{O}^{+} .2 \mathrm{H}_{2} \mathrm{O}\end{array}$ & Spanel and Smith 1997 \\
\hline ethyl acetate & $\mathrm{NO}^{+}$ & 2.1 & 118 & $\mathrm{NO}^{+} . \mathrm{CH}_{3} \mathrm{COOC}_{2} \mathrm{H}_{5}$ & Spanel and Smith 1998b \\
\hline hexanal & $\mathrm{NO}^{+}$ & 2.5 & 99 & $\mathrm{C}_{6} \mathrm{H}_{11} \mathrm{O}^{+}$ & Spanel and others 1997 \\
\hline hexen-1-ol*** & $\mathrm{NO}^{+}$ & 2.5 & 72 & $\mathrm{C}_{4} \mathrm{H}_{8} \mathrm{O}^{+}$ & Syft Technologies 2009 \\
\hline isobutanal & $\mathrm{O}_{2}^{+}$ & 3 & 72 & $\mathrm{C}_{4} \mathrm{H}_{8} \mathrm{O}^{+}$ & Syft Technologies 2009 \\
\hline isobutyl alcohol & $\mathrm{NO}^{+}$ & 2.4 & 73 & $\mathrm{C}_{4} \mathrm{H}_{9} \mathrm{O}^{+}$ & Syft Technologies 2009 \\
\hline methanol & $\mathrm{H}_{3} \mathrm{O}^{+}$ & 2.7 & $\begin{array}{c}33+51+ \\
65+69+ \\
83\end{array}$ & $\begin{array}{c}\mathrm{CH}_{5} \mathrm{O}^{+}, \mathrm{CH}_{3} \mathrm{OH} \cdot \mathrm{H}+\mathrm{H}_{2} \mathrm{O} \\
\left(\mathrm{CH}_{3} \mathrm{OH}\right)_{2} \cdot \mathrm{H}+. \mathrm{CH}_{3} \mathrm{OH} \cdot \mathrm{H} \\
+.\left(\mathrm{H}_{2} \mathrm{O}\right)_{2}, \\
\left(\mathrm{CH}_{3} \mathrm{OH}\right)_{2} \cdot \mathrm{H}+\mathrm{H}_{2} \mathrm{O}\end{array}$ & Spanel and Smith 1997 \\
\hline methional & $\mathrm{O}_{2}^{+}$ & 2.5 & 104 & $\mathrm{C}_{4} \mathrm{H}_{8} \mathrm{OS}^{+}$ & Syft Technologies 2009 \\
\hline methyl benzoate & $\mathrm{H}_{3} \mathrm{O}^{+}$ & 3.1 & 137 & $\mathrm{C}_{6} \mathrm{H}_{5} \mathrm{COOCH}_{3} \cdot \mathrm{H}^{+}$ & Spanel and Smith 1998b \\
\hline $\begin{array}{l}\text { methylbutanoic } \\
\text { acid }^{* * * * *}\end{array}$ & $\mathrm{NO}^{+}$ & 2.5 & 132 & $\mathrm{C}_{5} \mathrm{H}_{10} \mathrm{O}_{2} \cdot \mathrm{NO}^{+}$ & Syft Technologies 2009 \\
\hline nonadienal $* * * * *$ & $\mathrm{NO}^{+}$ & 2.5 & 168 & $\mathrm{C}_{9} \mathrm{H}_{14} \mathrm{O}_{\mathrm{NO}}{ }^{+}$ & Syft Technologies 2009 \\
\hline nonanal & $\mathrm{O}_{2}^{+}$ & 3.2 & 112 & $\mathrm{C}_{8} \mathrm{H}_{16}{ }^{+}$ & Syft Technologies 2009 \\
\hline phenylacetaldehyde & $\mathrm{NO}^{+}$ & 2.5 & 120 & $\mathrm{C}_{8} \mathrm{H}_{8} \mathrm{O}^{+}$ & Syft Technologies 2009 \\
\hline propanal & $\mathrm{NO}^{+}$ & 2.5 & 57 & $\mathrm{C}_{3} \mathrm{H}_{5} \mathrm{O}^{+}$ & Spanel and others 1997 \\
\hline propanoic acid & $\mathrm{O}_{2}^{+}$ & 2.2 & 74 & $\mathrm{C}_{2} \mathrm{H}_{5} \mathrm{COOH}^{+}$ & Spanel and Smith 1998b \\
\hline
\end{tabular}


*2-Pentenal is a mixture of $(E)$-2-pentenal and (Z)-2-pentenal

**Cyclic terpenes are a mixture of 2-carene, (R)-limonene, and terpinen-4-ol.

$* * *$ Hexen-1-ol is a mixture of $(E)$-2-hexenal, $(Z)$-2-hexenal, and (Z)-3-hexenal.

$* * * *$ Methylbutanoic acid is a mixture of 2-methylbutanoic acid and 3-methylbutanoic acid

$* * * * *$ Nonadienal is a mixture of $(E, Z)-2,6$-nonadienal and $(Z, Z)-3,6$-nonadienal

\subsection{Moisture Content}

Tomato peel was separated from the flesh using a paring knife. Approximately

$2.5 \mathrm{~g}$ of peel and a cross section slice of the tomato flesh $(\approx 5 \mathrm{~g})$ were placed on separate aluminum weighing dishes. Samples were run in triplicate for both peel and flesh samples. Moisture was measured by placing the aluminum dishes in an Isotemp® Oven (Fisher Scientific, Pittsburgh, PA, USA) at $105^{\circ} \mathrm{C}$ for $16 \mathrm{~h}$ (AOAC 1990). Results are shown in Table 3.2. 
Table 3.2 Weights of Tomato Samples for Lipid Extraction

\begin{tabular}{|c|c|c|c|}
\hline Variety & Sample & $\begin{array}{c}\text { Moisture } \\
(\%)\end{array}$ & $\begin{array}{c}\text { Tomato Added } \\
\text { (g) }\end{array}$ \\
\hline \multirow[b]{2}{*}{ Roma } & Peel & 93.52 & 42.77 \\
\hline & Flesh & 95.39 & 41.93 \\
\hline \multirow[b]{2}{*}{ Grape } & Peel & 92.01 & 43.47 \\
\hline & Flesh & 93.01 & 43.01 \\
\hline \multirow{2}{*}{$\begin{array}{c}\text { Vine } \\
\text { Ripened }\end{array}$} & Peel & 93.43 & 42.81 \\
\hline & Flesh & 95.16 & 42.03 \\
\hline \multirow[b]{2}{*}{ Cherry } & Peel & 90.24 & 44.33 \\
\hline & Flesh & 91.91 & 43.52 \\
\hline \multirow[b]{2}{*}{ Heirloom } & Peel & 92.77 & 43.12 \\
\hline & Flesh & 95.11 & 42.06 \\
\hline \multirow[b]{2}{*}{ FG06-602 } & Peel & 92.29 & 43.34 \\
\hline & Flesh & 95.59 & 41.84 \\
\hline \multirow[b]{2}{*}{ GEM 611} & Peel & 92.92 & 43.05 \\
\hline & Flesh & 95.47 & 41.90 \\
\hline \multirow[b]{2}{*}{ F006-609 } & Peel & 93.52 & 42.77 \\
\hline & Flesh & 95.86 & 41.73 \\
\hline \multirow[b]{2}{*}{ Hydroponic } & Peel & 94.43 & 42.36 \\
\hline & Flesh & 96.01 & 41.66 \\
\hline \multirow[b]{2}{*}{ Campari } & Peel & 91.03 & 43.94 \\
\hline & Flesh & 93.71 & 42.68 \\
\hline
\end{tabular}

\subsection{Lipoxygenase Activity}

\subsubsection{Extraction}

Three tomatoes worth of peel/flesh were pureed in a chopper. For the enzyme extract, five replicates of $2 \mathrm{~g}$ were taken from this aliquot of pureed tomatoes and added to a mortar with $2 \mathrm{~g}$ of homogenization buffer ( $0.1 \mathrm{M}$ Sodium Phosphate $\mathrm{pH} 7,0.2 \%$ Triton X-100). The mixture was ground with a mortar and pestle. An aliquot of $1 \mathrm{~mL}$ was taken and centrifuged for $5 \mathrm{~min}$ at 16,000 $\mathrm{xg}$ in an Eppendorf® Centrifuge 5415R (Eppendorf N.A., Hauppauge, New York, USA) at $23^{\circ} \mathrm{C}$. The least turbid portion of the 
supernatant was removed and placed in a clean $1.5 \mathrm{~mL}$ centrifuge tube to form the enzyme extract. The substrate solution was made by adding $155 \mu \mathrm{L}$ linoleic acid (SigmaAldrich, St. Louis, MO, USA), $257 \mu \mathrm{L}$ Tween 20 and $5 \mathrm{~mL}$ distilled water to an amber container, which was mixed by drawing in and out of a pipette. Then $0.6 \mathrm{~mL}$ of $1.0 \mathrm{~N}$ $\mathrm{NaOH}$ was added to clarify the substrate and the overall solution was diluted to $25 \mathrm{~mL}$ by adding $0.1 \mathrm{M}$ sodium phosphate buffer $\mathrm{pH}$ 7. Linoleic acid substrate solution was stored frozen in $1 \mathrm{ml}$ aliquots.

\subsubsection{Lipoxygenase Activity Quantification}

The sample was assayed by adding $75 \mu \mathrm{L}$ of the enzyme extract, $60 \mu \mathrm{L}$ of substrate solution, and $3 \mathrm{~mL} 0.1 \mathrm{M}$ sodium phosphate buffer $\mathrm{pH} 7$ in a glass cuvette. Lipoxygenase activity was quantified by measuring the change in absorbance at $234 \mathrm{~nm}$ using a UV-2450 UV-Visible Spectrophotometer (Shimadzu Scientific Instruments Inc., Addison, IL, USA). Samples were measured for $4 \mathrm{~min}$. Lipoxygenase activity was calculated as nmol of product formed per time on a fresh weight basis (nmols/g fwt $/ \mathrm{min}$ ). This was calculated by multiplying the average slope by 3 because the assay volume is 3 $\mathrm{mL}$. The absorbance is then converted to nmoles by dividing by 0.023 because the molar extinction coefficient of the lipoxygenase product is 23,000 (Anthon 2011). Next, the value is converted from seconds to minutes by multiplying by 60 . The value needs to be divided by the amount of tomato material in the assay. There were $75 \mu \mathrm{L}$ of homogenate added to the assay which is equal to $37.5 \mathrm{mg}$ of tomato in the assay, which accounts for the dilution of the added sodium phosphate buffer. 


\subsection{Fatty Acid Composition}

\subsubsection{Lipid Extraction and Total Fatty Acid Determination}

Tomato lipids were extracted using the procedure developed by Bligh and Dyer (1959). Each replicate contained multiple tomatoes to reach a specified amount of sample depending on the moisture content of each variety for a total of $40 \mathrm{~mL}$ of moisture from the tomato sample (See Appendix A for Table 3.2). The tomato sample was blended for $2 \mathrm{~min}$ with $50 \mathrm{~mL}$ chloroform and $100 \mathrm{~mL}$ methanol. Following blending, $50 \mathrm{~mL}$ chloroform was added. After $30 \mathrm{sec}, 50 \mathrm{~mL}$ distilled water was added. The extract was blended for another $30 \mathrm{sec}$ then transferred to centrifuge tubes to be centrifuged for 20 min at 9,000 RPM (Centrific ${ }^{\mathrm{TM}}$ Centrifuge, Fisher Scientific, Pittsburgh, PA, USA). The supernatant was filtered through Whatman No. 1 filter paper in a funnel with suction. The filtrate was transferred to a separatory funnel and let stand for a few minutes. The alcoholic layer was removed by aspiration and then added to a round bottom flask. The sample was evaporated using a Büchi Rotavapor® R-210/R-215 (Büchi Co., New Castle, DE, USA). The total fatty acid was quantified by subtracting the round bottom flask weight from the weight of dried sample/round bottom flask weight.

\subsubsection{Methylation}

The extracted fatty acids were determined using a fatty acid methyl ester (FAME) method (Allendorf and others 2011). Lipids extracted from the tomato peel/flesh were esterified by adding $10 \mathrm{~mL}$ of $4 \%$ methanolic-sulfuric acid and $1 \mathrm{~mL}$ of benzene to $0.50 \mathrm{~g}$ of extracted lipid solubilized in chloroform into a glass test tube with a Teflon screw cap. 
Samples were then boiled for $120 \mathrm{~min}$ at $80-90^{\circ} \mathrm{C}$. After the samples cooled, $1 \mathrm{ml}$ distilled water and $2 \mathrm{~mL}$ of hexane were added to help extract the methyl esters. One $\mathrm{mL}$ of the hexane layer was placed in a $1.5 \mathrm{~mL} \mathrm{GC}$ vial and evaporated under nitrogen.

Finally, $0.5 \mathrm{~mL}$ iso-octane was added to the dried sample to re-dilute it and the crimp top was crimped on.

\subsubsection{Fatty Acid Composition}

Methyl ester samples were analyzed using an HP-6890 GC equipped with a flame ionization detector (FID) (Hewlett Packard Co., Palo Alto, CA, USA). For automated injections an HP G 1513A autosampler and tray (Hewlett Packard Co., Palo Alto, CA, USA) were used. The components were then separated using an HP-FFAP $25 \mathrm{~m} \times 0.32$ mm x $0.5 \mu \mathrm{m}$ column (Agilent part number 19019F-112) with helium as the carrier gas. One $\mu \mathrm{L}$ of sample was injected with a split ratio of $20: 1$. The oven was set at $110^{\circ} \mathrm{C}$ for 1 min then increased by $5^{\circ} \mathrm{C} / \mathrm{min}$ to $220^{\circ} \mathrm{C}$ and held for $15 \mathrm{~min}$. The injector temperature was $220^{\circ} \mathrm{C}$ and the detector temperature was $240^{\circ} \mathrm{C}$. Run time was set at $30 \mathrm{~min}$, during the first 20 min the sample was analyzed and the last $10 \mathrm{~min}$ the column was cleaned at a maximum temperature of $280^{\circ} \mathrm{C}$. The retention times were compared with known fatty acid standards to identify the fatty acids present.

\subsection{Storage Testing}

Campari tomatoes were measured for volatile quantification, lipoxygenase activity, moisture content and total fatty acid determination on the day of purchase (Day 0) using the previous methods. Samples were then stored for $14 \mathrm{~d}$ in two separate conditions: room temperature at $20-23^{\circ} \mathrm{C}$, and refrigerated at $2-5^{\circ} \mathrm{C}$. Samples were stored 
for $14 \mathrm{~d}$ and then reevaluated for volatiles, lipoxygenase activity, moisture and total fatty acid. Day 0 and the two day 14 samples were compared for any changes due to storage conditions.

\subsection{Addition of Lipoxygenase and Linoleic Acid}

Two $\mathrm{mL}$ of lipoxygenase homogenate $(0.1 \mathrm{M}$ sodium phosphate $\mathrm{pH} 7,0.2 \%$ Triton X-100) was added prior to blending to $10.5 \mathrm{~mL}$ of water instead of $12.5 \mathrm{~mL}$ of water in the headspace volatile quantification method. For the linoleic acid addition, 5 $\mathrm{mL}$ of linoleic acid substrate solution $(155 \mu \mathrm{L}$ linoleic acid, $257 \mu \mathrm{L}$ Tween $20,5 \mathrm{~mL}$ distilled water, $0.6 \mathrm{~mL}$ of $1.0 \mathrm{~N} \mathrm{NaOH}$ and $25 \mathrm{~mL} 0.1 \mathrm{M}$ sodium phosphate buffer $\mathrm{pH} 7$ ) was added prior to blending to $7.5 \mathrm{~mL}$ of water instead of $12.5 \mathrm{~mL}$ of water.

\subsection{Statistical Analysis}

Data was analyzed by using one-way analysis of variance (ANOVA) and the Tukey's family error rate with the Minitab program (Minitab 16, Minitab Inc., Pennsylvania USA). Significance was defined as $p \leq 0.05$. Headspace volatiles were also analyzed using Pirouette® (Version 4.0, Infometrix Inc., Woodville, WA, USA). Soft independent modeling of class analogy algorithm (SIMCA) with a probability threshold of 0.95 was used to identify variety differences. 


\section{Chapter 4: Results and Discussion}

\subsection{Comparison of Peel and Flesh of Tomato}

\subsubsection{Peel Volatiles vs. Flesh Volatiles}

Volatile levels were significantly greater in peel than in flesh, when there was a significant difference (Tables 4.1 and 4.2). (Z)-3-Hexenal and methanol were significantly greater $(\mathrm{p} \leq 0.05)$ in peel than flesh for all 10 varieties, and 1-hexanol, 2methyl propanal, dimethyl sulfide, hexanal, hexen-1-ol, methional, methyl benzoate, and propanoic acid were significantly greater in 6 of the 10 varieties. The volatiles in tomato peel and flesh can be broken down into five categories: lipid derived, amino acid derived, carotenoid derived, lignin derived and esters. The majority of volatiles measured were lipid or amino acid derived volatiles with 10 and 20, respectively.

The lipoxygenase pathway is very important to the production of C-6 volatiles in tomatoes (Galliard and Matthew 1977). The lipid derived volatiles are formed from the breakdown of linoleic and linolenic acids which react with lipoxygenase to form 13hydroperoxy intermediates. The $13 \mathrm{C}$ compounds further react with other enzymes in the lipoxygenase pathway to form the lipid related volatile compounds. Of the 10 lipid derived volatiles, 8 had significantly higher levels in the peel than the flesh in at least one 
variety (Tables 4.1 and 4.2). (Z)-3-Hexenal was significantly different for all 10 varieties. 1-Hexanol, hexanal, hexen-1-ol, nonadienal, and (E)-2-hexenal were significantly different in a majority of the varieties. Similar findings were reported by Buttery and others (1988), who found that the skin contained considerably higher levels of C6 aldehydes and several-fold higher concentrations of C6 alcohols than the whole tomato or the interior pulp.

There were six amino acid derived volatiles that were significantly greater in the peel than the flesh in six or more varieties: 2-methyl propanal, acetone, dimethyl sulfide, isobutanal, methional, and propanoic acid (Tables 4.1 and 4.2). 2-Methyl-propanal, isobutanal, and propanoic acid are products of the precursor amino acid valine (Bernalte and others 1998, Gibson and others 1998, Urbach 1995). Dimethyl sulfide and methional are produced from methionine (Wong and Carson 1966, Mayer and others 2008).

The other reported volatiles that were greater in the peel than flesh fall into the categories of carotenoid, lignin, ester and pectin derived volatiles. Methyl benzoate was the only volatile of these that was significantly different in a majority of the varieties (Tables 4.1 and 4.2). The lignin derived volatile benzyl alcohol was the only volatile to be significantly greater in the flesh than peel and this was only for one variety. Overall there was no pattern among the volatiles that are not related to amino acids or lipids.

Thirteen volatiles were not significantly different in all 10 varieties: 1-butanol, 1propanol, 2,3-butanedione, 2-isobutylthiazole, 2-pentanol, 3-methylbutanal, ethanol, 
ethyl acetate, isobutyl alcohol, methyl butanoic acid, nonanal, phenylacetaldehyde, and propanal. The majority of the non-significant volatiles are amino acid derived.

Combining (Z)-3-hexenal, (Z)-3-hexenol, hexanal, 1-penten-3-one, 3methylbutanal, (E)-2-hexenal, 6-methyl-5-hepten-2-one, methyl salicylate, 2isobutylthiazole, and $\beta$-ionone at varying concentrations produces the aroma of a fresh, ripe tomato (Buttery 1993). Of these volatiles only (Z)-3-hexenal, (Z)-3-hexenol, hexanal, and 1-hexanol were significantly greater in the peel than the flesh in more than half the varieties. The others were either present in too low of amounts or were significantly different in only a few varieties. 
Table 4.1 Peel volatiles (ppm) of 10 tomato varieties. (Each volatile with different letters in Tables 4.1 and 4.2 are significantly different)

\begin{tabular}{|c|c|c|c|c|c|c|c|c|c|c|}
\hline Volatile & Campari & FG06-602 & Hydroponic & Vine Ripened & Heirloom & Roma & Grape & Cherry & GEM 611 & F006-609 \\
\hline (E)-2-heptenal & $6^{\mathrm{cd}}$ & $5^{\mathrm{cd}}$ & $5^{\mathrm{cd}}$ & $5^{\mathrm{cd}}$ & $5^{\mathrm{cd}}$ & $7^{\mathrm{cd}}$ & $19^{\mathrm{a}}$ & $7^{\mathrm{cd}}$ & $3^{\mathrm{cd}}$ & $4^{\text {cd }}$ \\
\hline (E)-2-hexenal & $394^{\mathrm{a}}$ & $273^{\mathrm{abc}}$ & $295^{\mathrm{abc}}$ & $273^{\mathrm{abc}}$ & $290^{\mathrm{abc}}$ & $322^{\mathrm{ab}}$ & $258^{\text {bcde }}$ & $181^{\text {bcde }}$ & $139^{\text {cde }}$ & $163^{\text {cde }}$ \\
\hline (Z)-3-hexenal & $4048^{\mathrm{a}}$ & $3482^{\mathrm{ab}}$ & $3423^{\mathrm{ab}}$ & $3418^{\mathrm{bc}}$ & $2942^{\mathrm{ab}}$ & $2690^{\mathrm{bc}}$ & $2470^{\mathrm{cd}}$ & $2134^{\mathrm{e}}$ & $2023^{\text {cde }}$ & $1995^{\text {cde }}$ \\
\hline 1-butanol & $14^{\mathrm{ef}}$ & $18^{\mathrm{def}}$ & $24^{\text {cdef }}$ & $27^{\text {bcde }}$ & $40^{\mathrm{ab}}$ & $21^{\text {cdef }}$ & $19^{\mathrm{ef}}$ & $12^{\mathrm{f}}$ & $8^{\mathrm{f}}$ & $15^{\mathrm{ef}}$ \\
\hline 1-hexanol & $30^{\mathrm{a}}$ & $22^{\mathrm{abc}}$ & $17^{\text {bcde }}$ & $23^{\mathrm{abc}}$ & $19^{\mathrm{bcd}}$ & $23^{\mathrm{ab}}$ & $22^{\text {cdef }}$ & $16^{\text {cde }}$ & $10^{\text {defg }}$ & $9^{\text {efg }}$ \\
\hline 1-penten-3-one & $47^{\text {cde }}$ & $48^{\mathrm{de}}$ & $51^{\text {cde }}$ & $45^{\mathrm{de}}$ & $48^{\mathrm{de}}$ & $48^{\text {cde }}$ & $213^{\mathrm{a}}$ & $15^{\mathrm{e}}$ & $39^{\mathrm{de}}$ & $39^{\mathrm{de}}$ \\
\hline 1-propanol & $22^{\mathrm{abc}}$ & $55^{\mathrm{a}}$ & $22^{\mathrm{abc}}$ & $28^{\mathrm{abc}}$ & $28^{\mathrm{abc}}$ & $24^{\mathrm{abc}}$ & $14^{\mathrm{bc}}$ & $54^{\mathrm{a}}$ & $15^{\mathrm{bc}}$ & $43^{\mathrm{ab}}$ \\
\hline 2,3-butanediol & $11^{\mathrm{ab}}$ & $11^{\mathrm{a}}$ & $9^{\mathrm{abcd}}$ & $9^{\mathrm{abc}}$ & $8^{\text {abcde }}$ & $9^{\mathrm{abc}}$ & $8^{\text {abcdef }}$ & $7^{\text {abcdef }}$ & $10^{\mathrm{abc}}$ & $7^{\text {abcdef }}$ \\
\hline 2,3-butanedione & $16^{\mathrm{abc}}$ & $11^{\mathrm{bc}}$ & $17^{\mathrm{bc}}$ & $12^{\mathrm{bc}}$ & $13^{\mathrm{abc}}$ & $13^{\mathrm{abc}}$ & $26^{\mathrm{ab}}$ & $5^{\mathrm{c}}$ & $9^{\mathrm{bc}}$ & $9^{\mathrm{bc}}$ \\
\hline 2-isobutylthiazole & $18^{\mathrm{abc}}$ & $1^{\mathrm{d}}$ & $3^{\mathrm{cd}}$ & $16^{\mathrm{abc}}$ & $5^{\mathrm{bcd}}$ & $2^{\text {cd }}$ & $11^{\mathrm{bcd}}$ & $11^{\mathrm{abcd}}$ & $2^{\text {cd }}$ & $10^{\mathrm{abcd}}$ \\
\hline 2-methylpropanal & $293^{\mathrm{a}}$ & $180^{\mathrm{cd}}$ & $151^{\text {cde }}$ & $202^{\mathrm{bc}}$ & $186^{\text {bcd }}$ & $233^{\mathrm{ab}}$ & $160^{\mathrm{def}}$ & $168^{\mathrm{cd}}$ & $90^{\text {efg }}$ & $93^{\text {efg }}$ \\
\hline 2-pentanol & $21^{\text {abcd }}$ & $13^{\text {cdefg }}$ & $20^{\text {abcde }}$ & $19^{\text {abcde }}$ & $27^{\mathrm{a}}$ & $23^{\mathrm{abc}}$ & $18^{\text {abcdefg }}$ & $8^{\mathrm{efg}}$ & $9^{\text {defg }}$ & $9^{\text {defg }}$ \\
\hline 2-pentanone & $16^{\mathrm{ab}}$ & $16^{\mathrm{a}}$ & $14^{\mathrm{abcd}}$ & $15^{\mathrm{abc}}$ & $12^{\text {abcdef }}$ & $16^{\mathrm{abc}}$ & $16^{\mathrm{abcde}}$ & $9^{\text {cdefg }}$ & $11^{\text {abcdefg }}$ & $9^{\text {bcdefg }}$ \\
\hline 2-pentenal & $42^{\mathrm{abcd}}$ & $45^{\mathrm{abc}}$ & $40^{\text {abcdef }}$ & $37^{\text {bcdef }}$ & $35^{\text {bcdefg }}$ & $36^{\text {abcdef }}$ & $68^{\mathrm{a}}$ & $20^{\text {efgh }}$ & $28^{\text {bcdefgh }}$ & $25^{\text {cdefgh }}$ \\
\hline 3-methylbutanal & $42^{\mathrm{abcd}}$ & $21^{\mathrm{bcd}}$ & $48^{\mathrm{abcd}}$ & $30^{\mathrm{bcd}}$ & $29^{\mathrm{bcd}}$ & $36^{\mathrm{bcd}}$ & $68^{\mathrm{ab}}$ & $8^{\mathrm{d}}$ & $15^{\mathrm{bcd}}$ & $12^{\mathrm{cd}}$ \\
\hline 6-methyl-5-hepten-2-one & $24^{\text {cd }}$ & $68^{\mathrm{a}}$ & $13^{\mathrm{d}}$ & $18^{\mathrm{d}}$ & $16^{\mathrm{d}}$ & $15^{\mathrm{d}}$ & $29^{\mathrm{d}}$ & $16^{\mathrm{d}}$ & $49^{\mathrm{abc}}$ & $45^{\mathrm{bc}}$ \\
\hline acetaldehyde & $264^{\text {abcdef }}$ & $442^{\mathrm{a}}$ & $287^{\text {abcdef }}$ & $237^{\text {abcdef }}$ & $217^{\text {abcdef }}$ & $212^{\text {abcdef }}$ & $313^{\mathrm{abc}}$ & $345^{\text {abcd }}$ & $229^{\text {abcdef }}$ & $325^{\text {abcde }}$ \\
\hline acetone & $477^{\mathrm{a}}$ & $337^{\text {abcdef }}$ & $350^{\text {abcdef }}$ & $395^{\mathrm{abcd}}$ & $348^{\text {abcde }}$ & $335^{\text {abcdef }}$ & $375^{\text {cdefg }}$ & $254^{\text {efgh }}$ & $454^{\mathrm{abc}}$ & $254^{\text {defgh }}$ \\
\hline
\end{tabular}

Continued 
Table 4.1 Continued

\begin{tabular}{|c|c|c|c|c|c|c|c|c|c|c|}
\hline Volatile & Campari & FG06-602 & Hydroponic & Vine Ripened & Heirloom & Roma & Grape & Cherry & GEM 611 & F006-609 \\
\hline benzaldehyde & $16^{\mathrm{abcd}}$ & $17^{\mathrm{abc}}$ & $15^{\text {abcde }}$ & $21^{\mathrm{ab}}$ & $14^{\text {bcde }}$ & $20^{\mathrm{a}}$ & $18^{\text {bcdef }}$ & $8^{\operatorname{defg}}$ & $11^{\text {cdefg }}$ & $7^{\text {defg }}$ \\
\hline benzyl alcohol & $10^{\mathrm{de}}$ & $43^{\mathrm{ab}}$ & $5^{\mathrm{e}}$ & $6^{\mathrm{e}}$ & $12^{\mathrm{de}}$ & $7^{\mathrm{e}}$ & $9^{e}$ & $2^{\mathrm{e}}$ & $30^{\mathrm{bc}}$ & $23^{\mathrm{cd}}$ \\
\hline cyclic terpenes & $35^{\mathrm{a}}$ & $10^{\mathrm{bc}}$ & $6^{\mathrm{c}}$ & $18^{\mathrm{b}}$ & $5^{\mathrm{c}}$ & $6^{\mathrm{c}}$ & $6^{\mathrm{c}}$ & $4^{\mathrm{c}}$ & $4^{c}$ & $5^{c}$ \\
\hline dimethyl disulfide & $6^{\text {bcde }}$ & $15^{\mathrm{abcd}}$ & $8^{\text {abcde }}$ & $16^{\mathrm{abc}}$ & $6^{\text {cde }}$ & $7^{\text {bcde }}$ & $23^{\mathrm{a}}$ & $18^{\mathrm{ab}}$ & $9^{\text {abcde }}$ & $13^{\text {abcde }}$ \\
\hline dimethyl sulfide & $591^{\mathrm{a}}$ & $332^{\text {cd }}$ & $326^{\mathrm{cd}}$ & $500^{\mathrm{ab}}$ & $403^{\mathrm{bc}}$ & $534^{\mathrm{a}}$ & $415^{\text {cde }}$ & $336^{\mathrm{cd}}$ & $158^{\text {efg }}$ & $161^{\text {efg }}$ \\
\hline ethanol & $123^{\mathrm{a}}$ & $409^{a}$ & $122^{\mathrm{a}}$ & $108^{\mathrm{a}}$ & $99^{\mathrm{a}}$ & $92^{\mathrm{a}}$ & $148^{\mathrm{a}}$ & $193^{\mathrm{a}}$ & $137^{\mathrm{a}}$ & $274^{\mathrm{a}}$ \\
\hline ethyl acetate & $12^{\mathrm{ab}}$ & $59^{\mathrm{a}}$ & $9^{\mathrm{ab}}$ & $13^{\mathrm{ab}}$ & $10^{\mathrm{ab}}$ & $11^{\mathrm{ab}}$ & $11^{\mathrm{ab}}$ & $7^{\mathrm{ab}}$ & $15^{\mathrm{ab}}$ & $20^{\mathrm{ab}}$ \\
\hline hexanal & $4270^{\mathrm{a}}$ & $2492^{\mathrm{bc}}$ & $2185^{\mathrm{c}}$ & $2994^{\mathrm{bc}}$ & $2550^{\mathrm{bc}}$ & $3550^{\mathrm{ab}}$ & $2528^{\mathrm{cd}}$ & $2242^{b c}$ & $1051^{\mathrm{de}}$ & $1076^{\mathrm{de}}$ \\
\hline hexen-1-ol & $28^{\mathrm{b}}$ & $42^{\mathrm{a}}$ & $20^{\text {bcd }}$ & $28^{b}$ & $21^{\text {bcd }}$ & $25^{\operatorname{def}}$ & $24^{\text {bcd }}$ & $16^{\text {cde }}$ & $29^{b}$ & $25^{\mathrm{bc}}$ \\
\hline isobutanal & $293^{\mathrm{a}}$ & $180^{\text {bcd }}$ & $151^{\text {cde }}$ & $202^{\mathrm{bc}}$ & $186^{\text {bcd }}$ & $233^{\mathrm{ab}}$ & $160^{\text {def }}$ & $168^{\mathrm{cd}}$ & $90^{\text {efg }}$ & $93^{\text {efg }}$ \\
\hline isobutyl alcohol & $13^{\text {ef }}$ & $16^{\operatorname{def}}$ & $22^{\text {cdef }}$ & $25^{\text {bcde }}$ & $36^{\mathrm{ab}}$ & $19^{\text {cdef }}$ & $17^{\text {ef }}$ & $11^{\mathrm{f}}$ & $7^{\mathrm{f}}$ & $14^{\mathrm{ef}}$ \\
\hline methanol & $31400^{\mathrm{de}}$ & $48300^{\mathrm{ab}}$ & $31275^{\mathrm{de}}$ & $55360^{\mathrm{a}}$ & $24080^{\mathrm{e}}$ & $29640^{\mathrm{de}}$ & $40150^{\mathrm{de}}$ & $39640^{\mathrm{bcd}}$ & $44467^{\text {bc }}$ & $36425^{\mathrm{cd}}$ \\
\hline methional & $46^{\mathrm{ab}}$ & $38^{\text {bcd }}$ & $24^{\operatorname{def}}$ & $55^{\mathrm{a}}$ & $22^{\text {defg }}$ & $40^{\mathrm{abc}}$ & $44^{\text {cdef }}$ & $27^{\text {cde }}$ & $18^{\text {efgh }}$ & $17^{\text {efgh }}$ \\
\hline methyl benzoate & $133^{\mathrm{a}}$ & $50^{\mathrm{d}}$ & $40^{\mathrm{de}}$ & $95^{\mathrm{b}}$ & $53^{\mathrm{cd}}$ & $68^{\mathrm{bc}}$ & $64^{\mathrm{de}}$ & $55^{\mathrm{cd}}$ & $21^{\mathrm{ef}}$ & $20^{\mathrm{ef}}$ \\
\hline methylbutanoic acid & $2^{\text {de }}$ & $14^{\mathrm{bc}}$ & $4^{\mathrm{de}}$ & $5^{\mathrm{d}}$ & $4^{\mathrm{de}}$ & $3^{\mathrm{de}}$ & $2^{\mathrm{e}}$ & $1^{\mathrm{e}}$ & $3^{\mathrm{de}}$ & $11^{\mathrm{c}}$ \\
\hline nonadienal & $31^{\mathrm{a}}$ & $21^{\mathrm{abc}}$ & $24^{\mathrm{ab}}$ & $25^{\mathrm{ab}}$ & $22^{\mathrm{abc}}$ & $17^{\mathrm{bc}}$ & $16^{\mathrm{cd}}$ & $8^{\mathrm{de}}$ & $4^{\mathrm{de}}$ & $6^{\mathrm{de}}$ \\
\hline nonanal & $11^{\mathrm{abc}}$ & $15^{\mathrm{ab}}$ & $4^{\mathrm{c}}$ & $11^{\mathrm{abc}}$ & $8^{\mathrm{abc}}$ & $10^{\mathrm{abc}}$ & $25^{\mathrm{a}}$ & $9^{\mathrm{abc}}$ & $9^{\mathrm{abc}}$ & $7^{\mathrm{abc}}$ \\
\hline phenylacetaldehyde & $16^{\mathrm{ab}}$ & $14^{\mathrm{abc}}$ & $11^{\text {bcdef }}$ & $18^{\mathrm{a}}$ & $10^{\text {cdef }}$ & $12^{\text {abcd }}$ & $17^{\text {bcde }}$ & $8^{\text {cdefg }}$ & $7^{\text {defgh }}$ & $8^{\text {cdefgh }}$ \\
\hline propanal & $17^{\mathrm{abc}}$ & $15^{\mathrm{abc}}$ & $15^{\mathrm{abc}}$ & $12^{\mathrm{abc}}$ & $13^{\mathrm{abc}}$ & $14^{\mathrm{abc}}$ & $27^{\mathrm{abc}}$ & $9^{\mathrm{abc}}$ & $8^{\mathrm{abc}}$ & $9^{\mathrm{abc}}$ \\
\hline propanoic acid & $14^{\mathrm{ab}}$ & $17^{\mathrm{a}}$ & $15^{\mathrm{ab}}$ & $15^{\mathrm{ab}}$ & $13^{\mathrm{abc}}$ & $14^{\mathrm{ab}}$ & $12^{\text {bcde }}$ & $8^{\text {cde }}$ & $19^{\mathrm{a}}$ & $16^{\mathrm{ab}}$ \\
\hline
\end{tabular}


Table 4.2 Flesh volatiles (ppm) of 10 tomato varieties. (Each volatile with different letters in Tables 4.1 and 4.2 are significantly different)

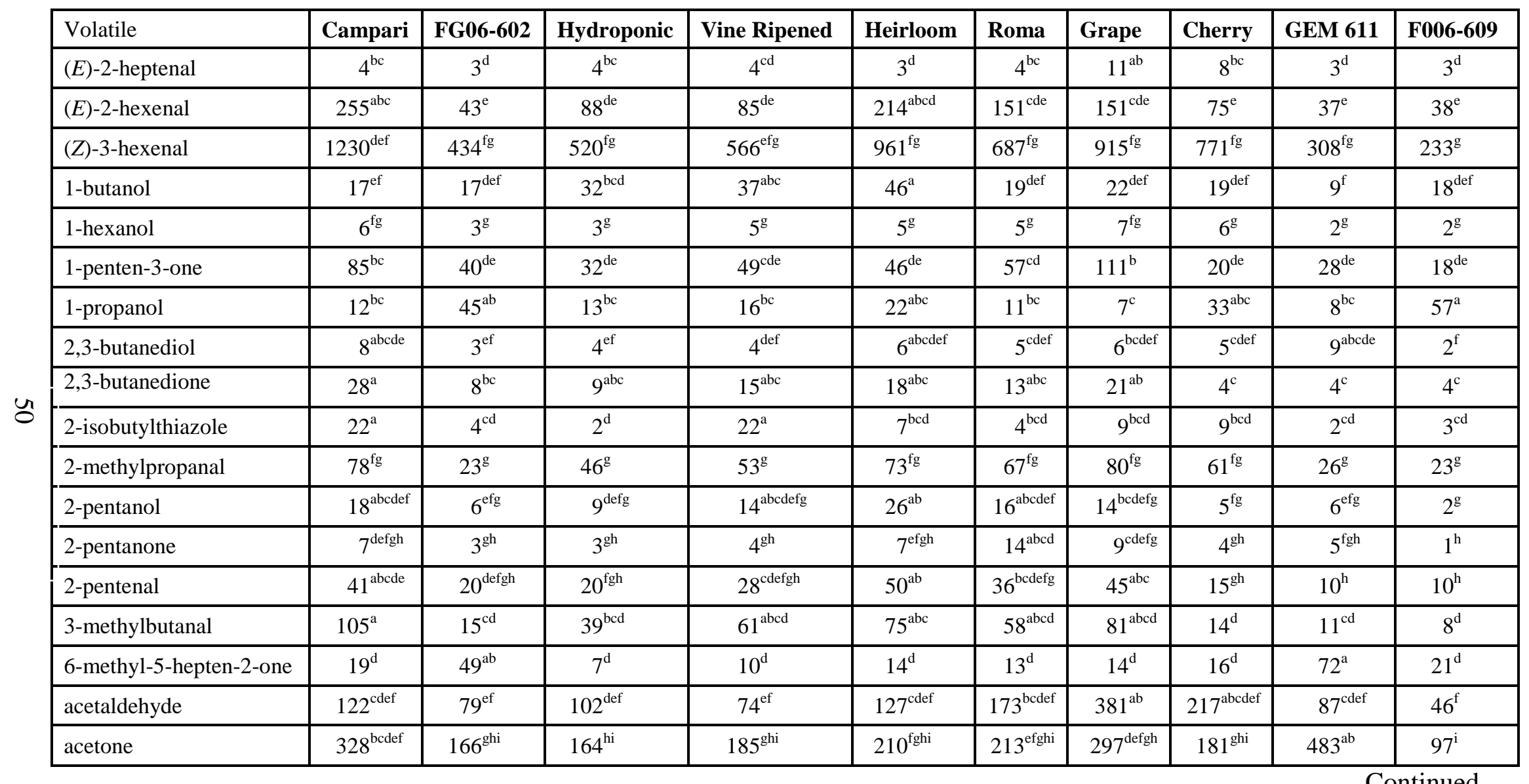


Table 4.2 Continued

\begin{tabular}{|c|c|c|c|c|c|c|c|c|c|c|}
\hline Volatile & Campari & FG06-602 & Hydroponic & Vine Ripened & Heirloom & Roma & Grape & Cherry & GEM 611 & F006-609 \\
\hline benzaldehyde & $10^{\text {cdefg }}$ & $7^{\mathrm{efg}}$ & $4^{\mathrm{fg}}$ & $8^{\text {efg }}$ & $11^{\text {cdefg }}$ & $10^{\text {cdefg }}$ & $8^{\operatorname{defg}}$ & $5^{\mathrm{fg}}$ & $3^{\mathrm{fg}}$ & $2^{g}$ \\
\hline benzyl alcohol & $9^{\mathrm{de}}$ & $40^{\mathrm{ab}}$ & $2^{\mathrm{e}}$ & $6^{\mathrm{e}}$ & $10^{\mathrm{de}}$ & $8^{\mathrm{de}}$ & $6^{\mathrm{e}}$ & $2^{\mathrm{e}}$ & $53^{\mathrm{a}}$ & $15^{\text {cde }}$ \\
\hline cyclic terpenes & $5^{\mathrm{c}}$ & $5^{\mathrm{c}}$ & $4^{\mathrm{c}}$ & $10^{\mathrm{bc}}$ & $1^{\mathrm{c}}$ & $1^{\mathrm{c}}$ & $2^{\mathrm{c}}$ & $2^{\mathrm{c}}$ & $4^{c}$ & $3^{\mathrm{c}}$ \\
\hline dimethyl disulfide & $4^{\mathrm{de}}$ & $3^{\mathrm{de}}$ & $3^{\mathrm{e}}$ & $2^{\mathrm{e}}$ & $4^{\mathrm{e}}$ & $5^{\mathrm{cde}}$ & $9^{\text {abcde }}$ & $4^{\mathrm{e}}$ & $4^{\text {cde }}$ & $2^{\mathrm{e}}$ \\
\hline dimethyl sulfide & $154^{\mathrm{fg}}$ & $39^{\mathrm{g}}$ & $90^{\mathrm{fg}}$ & $126^{\mathrm{fg}}$ & $149^{\mathrm{fg}}$ & $146^{\mathrm{fg}}$ & $205^{\mathrm{def}}$ & $137^{\mathrm{fg}}$ & $36^{\mathrm{g}}$ & $35^{\mathrm{g}}$ \\
\hline ethanol & $43^{\mathrm{a}}$ & $38^{\mathrm{a}}$ & $67^{\mathrm{a}}$ & $39^{\mathrm{a}}$ & $79^{\mathrm{a}}$ & $56^{\mathrm{a}}$ & $196^{\mathrm{a}}$ & $296^{\mathrm{a}}$ & $44^{\mathrm{a}}$ & $30^{\mathrm{a}}$ \\
\hline ethyl acetate & $4^{b}$ & $5^{\mathrm{ab}}$ & $4^{b}$ & $5^{\mathrm{ab}}$ & $8^{\mathrm{ab}}$ & $5^{\mathrm{ab}}$ & $5^{\mathrm{ab}}$ & $3^{\mathrm{b}}$ & $6^{\mathrm{ab}}$ & $6^{\mathrm{ab}}$ \\
\hline hexanal & $772^{\mathrm{e}}$ & $218^{\mathrm{e}}$ & $506^{\mathrm{e}}$ & $566^{\mathrm{de}}$ & $724^{\mathrm{e}}$ & $732^{\mathrm{e}}$ & $1039^{\text {de }}$ & $835^{\mathrm{e}}$ & $182^{\mathrm{e}}$ & $177^{\mathrm{e}}$ \\
\hline hexen-1-ol & $14^{\text {cdef }}$ & $11^{\text {def }}$ & $5^{\mathrm{f}}$ & $6^{\mathrm{ef}}$ & $12^{\mathrm{def}}$ & $8^{\mathrm{f}}$ & $11^{\text {def }}$ & $5^{\mathrm{ef}}$ & $13^{\text {cdef }}$ & $5^{\mathrm{ef}}$ \\
\hline isobutanal & $78^{\mathrm{fg}}$ & $23^{\mathrm{g}}$ & $46^{\mathrm{g}}$ & $53^{g}$ & $73^{\mathrm{fg}}$ & $67^{\mathrm{fg}}$ & $80^{\mathrm{fg}}$ & $61^{\mathrm{bc}}$ & $26^{\mathrm{g}}$ & $23^{\mathrm{g}}$ \\
\hline isobutyl alcohol & $15^{\mathrm{ef}}$ & $16^{\mathrm{def}}$ & $29^{\mathrm{bcd}}$ & $34^{\mathrm{abc}}$ & $42^{\mathrm{a}}$ & $17^{\mathrm{def}}$ & $20^{\mathrm{def}}$ & $18^{\mathrm{def}}$ & $8^{\mathrm{f}}$ & $16^{\mathrm{def}}$ \\
\hline methanol & $4140^{\mathrm{f}}$ & $9253^{\mathrm{f}}$ & $6604^{\mathrm{f}}$ & $7366^{\mathrm{f}}$ & $7080^{\mathrm{f}}$ & $8370^{\mathrm{f}}$ & $8418^{\mathrm{f}}$ & $6254^{\mathrm{f}}$ & $10533^{\mathrm{f}}$ & $8905^{\mathrm{f}}$ \\
\hline methional & $6^{\text {gh }}$ & $3^{\text {h }}$ & $3^{\mathrm{h}}$ & $5^{\mathrm{h}}$ & $6^{\mathrm{h}}$ & $9^{\mathrm{fgh}}$ & $11^{\mathrm{fgh}}$ & $4^{\mathrm{h}}$ & $3^{\mathrm{h}}$ & $2^{\mathrm{h}}$ \\
\hline methyl benzoate & $25^{\mathrm{ef}}$ & $9^{f}$ & $13^{\mathrm{f}}$ & $24^{\mathrm{ef}}$ & $17^{\mathrm{ef}}$ & $17^{\mathrm{ef}}$ & $23^{\mathrm{ef}}$ & $16^{\mathrm{ef}}$ & $7^{\mathrm{f}}$ & $8^{\mathrm{f}}$ \\
\hline methylbutanoic acid & $2^{\mathrm{de}}$ & $21^{\mathrm{a}}$ & $4^{\mathrm{de}}$ & $4^{\mathrm{de}}$ & $4^{\mathrm{de}}$ & $2^{\mathrm{de}}$ & $1^{\mathrm{e}}$ & $1^{\mathrm{e}}$ & $1^{\mathrm{de}}$ & $18^{\mathrm{ab}}$ \\
\hline nonadienal & $4^{\mathrm{de}}$ & $0^{\mathrm{e}}$ & $0^{\mathrm{e}}$ & $1^{\mathrm{e}}$ & $3^{\mathrm{de}}$ & $1^{\mathrm{e}}$ & $3^{\mathrm{de}}$ & $3^{\mathrm{de}}$ & $0^{\mathrm{e}}$ & $0^{\mathrm{e}}$ \\
\hline nonanal & $8^{\mathrm{abc}}$ & $10^{\mathrm{abc}}$ & $7^{\mathrm{abc}}$ & $7^{\mathrm{abc}}$ & $6^{\mathrm{bc}}$ & $9^{\mathrm{abc}}$ & $15^{\mathrm{ab}}$ & $7^{\mathrm{abc}}$ & $13^{\mathrm{abc}}$ & $8^{\mathrm{abc}}$ \\
\hline phenylacetaldehyde & $5^{\mathrm{fgh}}$ & $3^{\text {gh }}$ & $3^{\mathrm{h}}$ & $4^{\text {gh }}$ & $3^{\text {gh }}$ & $4^{\text {gh }}$ & $7^{\text {defgh }}$ & $4^{\text {efgh }}$ & $1^{\mathrm{h}}$ & $3^{\text {gh }}$ \\
\hline propanal & $21^{\mathrm{a}}$ & $7^{\mathrm{abc}}$ & $8^{\mathrm{abc}}$ & $10^{\mathrm{abc}}$ & $19^{\mathrm{abc}}$ & $22^{\mathrm{ab}}$ & $21^{\mathrm{ab}}$ & $7^{\mathrm{abc}}$ & $4^{\mathrm{bc}}$ & $3^{\mathrm{c}}$ \\
\hline propanoic acid & $6^{\mathrm{de}}$ & $7^{\text {cde }}$ & $6^{\mathrm{de}}$ & $6^{\mathrm{de}}$ & $6^{\mathrm{de}}$ & $6^{\text {cde }}$ & $7^{\text {cde }}$ & $4^{\mathrm{e}}$ & $12^{\text {abcd }}$ & $4^{\mathrm{e}}$ \\
\hline
\end{tabular}




\subsubsection{Effect of Lipoxygenase Activity on Volatile Concentration}

Lipoxygenase (LOX) is the first enzyme in the pathway which creates lipid volatiles in tomatoes therefore it may play a role in the differences that occur in the peel and flesh. LOX activity was significantly higher in peel than flesh for all 10 varieties (Table 4.3). Others have found similar results, where the locular material has no LOX activity, while the skin with outer flesh has $71 \%$ of the activity, but when the flesh was removed from the skin the activity was drastically lower for the relatively pure skin (Hatanaka and others 1992). This suggests that LOX activity is greatest in the fleshy tissue adjacent to the skin. The peel portion in this study contained small amounts of flesh next to the peel which may be why the peel portion was significantly greater than the flesh. These results for LOX are different from those for hydroperoxide lyase (HPL) activity, which was evenly distributed throughout the tomato (Hatanaka and others 1992). LOX produces 9 and 13-hydroperoxides which then react with HPL to form C9 and C6 aldehydes, respectively. HPL activity is critical because it helps in the creation of the fresh, green C6 aldehydes, such as hexanal and (Z)-3-hexenal in the lipoxygenase pathway. 
Table 4.3 Lipoxygenase activity (nmol/g fwt/min) in different varieties of tomato

\begin{tabular}{|l|c|c|}
\hline \multirow{2}{*}{} & \multicolumn{2}{|c|}{ Lipoxygenase Activity } \\
\cline { 2 - 3 } & Peel & Flesh \\
\hline Campari & $144^{\mathrm{ab}}$ & $63^{\mathrm{de}}$ \\
\hline FG06-602 & $130^{\mathrm{ab}}$ & $69^{\mathrm{de}}$ \\
\hline Hydroponic & $151^{\mathrm{a}}$ & $56^{\mathrm{de}}$ \\
\hline Vine Ripened & $139^{\mathrm{ab}}$ & $71^{\mathrm{de}}$ \\
\hline Heirloom & $143^{\mathrm{ab}}$ & $53^{\mathrm{e}}$ \\
\hline Roma & $166^{\mathrm{a}}$ & $96^{\mathrm{cd}}$ \\
\hline Grape & $138^{\mathrm{ab}}$ & $93^{\mathrm{cd}}$ \\
\hline Cherry & $163^{\mathrm{a}}$ & $77^{\mathrm{de}}$ \\
\hline GEM 611 & $110^{\mathrm{bc}}$ & $65^{\mathrm{de}}$ \\
\hline F006-609 & $136^{\mathrm{ab}}$ & $84^{\mathrm{de}}$ \\
\hline
\end{tabular}

${ }^{\text {a }}$ Samples with different letters in the table are significantly different

Lipoxygenase activity may have a significant effect on the formation of volatiles in the lipoxygenase pathway, such as (Z)-3-hexenal which originates from linolenic acid (Figure 2.1). There is a distinct separation between the peel and flesh with peel being greater than flesh in both lipoxygenase activity and the concentration of (Z)-3-hexenal (Figure 4.1). However, the correlation between (Z)-3-hexenal and lipoxygenase activity is not significant within the flesh or peel groups. Similar results were found with hexanal, 1-hexanol, hexen-1-ol, (E)-2-hexenal, and nonadienal. 


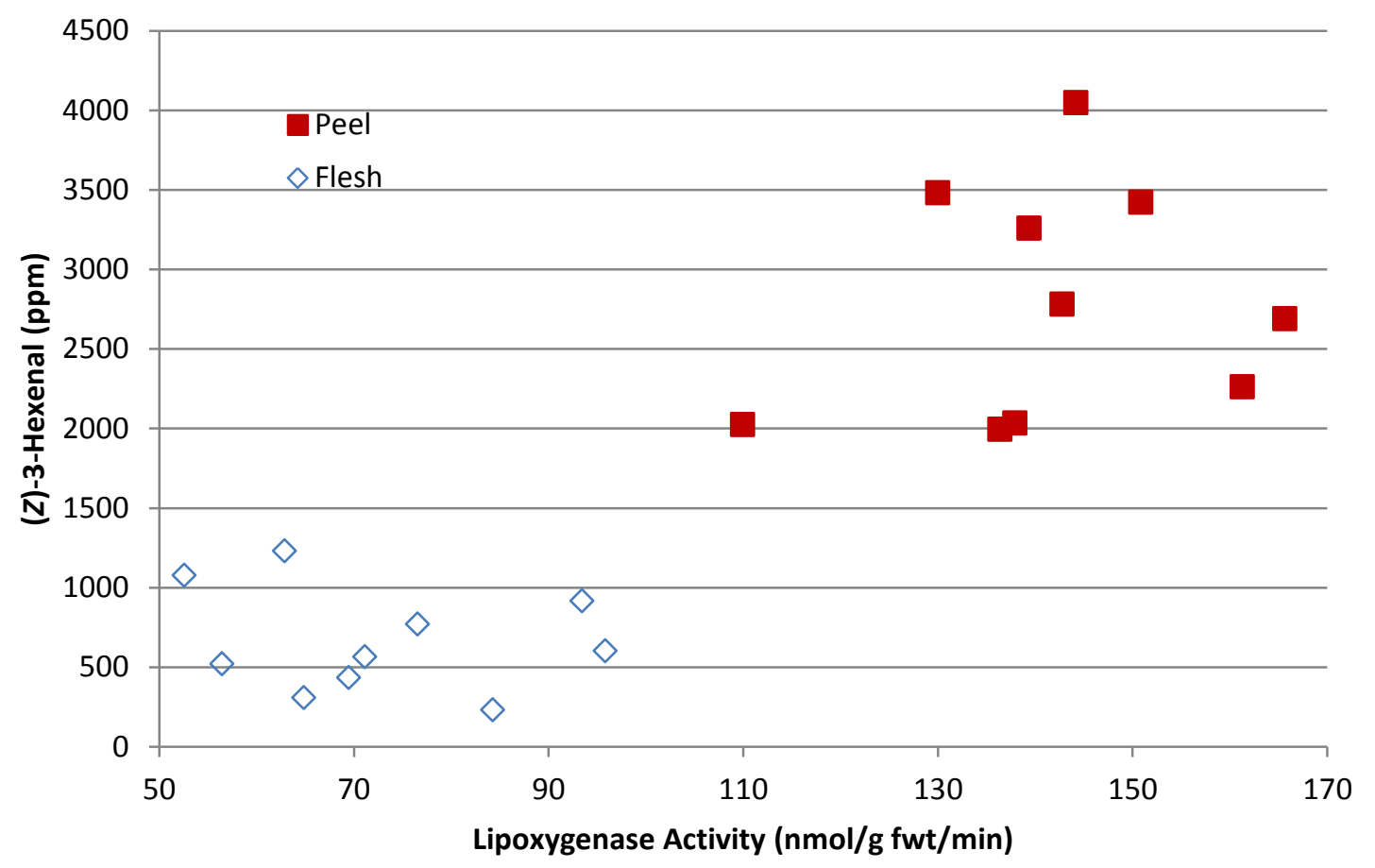

Figure 4.1 Effect of lipoxygenase activity on (Z)-3-hexenal formation in flesh (diamond) and peel (square)

To test the effect of lipoxygenase on lipoxygenase generated volatiles, an exogenous lipoxygenase homogenate was added (Table 4.4). Lipoxygenase addition had no significant effect on the lipoxygenase generated volatiles for either peel or flesh. This is somewhat consistent with a study where there was a steady decrease in the concentrations of hexanal, $(Z)$-3-hexenal, $(E)$-2-hexenal, and 1-penten-3-one with the addition of lipoxygenase, alcohol dehydrogenase or lipoxygenase/alcohol dehydrogenase in red tomatoes, as these volatiles also tended to decrease in this study (Yilmaz and others 2002). Tomatoes naturally containing varying concentrations of lipoxygenase, 
hydroperoxide lyase and alcohol dehydrogenase were found to have no significant correlation with hexanal, (Z)-3-hexenal, (E)-2-hexenal, $(E)$-2-heptenal, pentenone, or (Z)3-hexenol (Yilmaz and others 2001). However, when linoleic and linolenic acid was added, levels of hexanal and hexenal were much lower in tomatoes with low levels of lipoxygenase activity than tomatoes with high levels of lipoxygenase, thus there is some effect (Chen and others 2004).

Table 4.4 Effect of lipoxygenase addition on the lipoxygenase generated volatiles (ppm). There were no significant differences between the control and lipoxygenase addition.

\begin{tabular}{|l|c|c|c|c|}
\hline Volatile & Control Peel & Peel with Addition & Control Flesh & Flesh with Addition \\
\hline hexanal & 4398 & 3980 & 748 & 931 \\
\hline 1-hexanol & 32 & 37 & 6 & 7 \\
\hline$(E)$-2-heptenal & 8 & 6 & 4 & 4 \\
\hline (Z)-3-hexenal & 3650 & 3480 & 1172 & 1122 \\
\hline$(E)$-2-hexenal & 391 & 340 & 200 & 190 \\
\hline (Z)-3-hexen-1-ol & 30 & 36 & 11 & 13 \\
\hline (E)-2-pentenal & 42 & 40 & 40 & 39 \\
\hline 1-penten-3-one & 64 & 31 & 89 & 87 \\
\hline
\end{tabular}

\subsubsection{Effect of Total Fatty Acid Content and Fatty Acid Profile on Volatile Concentration}

Peel total fatty acid content was significantly greater than flesh in six of the varieties (Table 4.5). No other researchers have looked at the variations in total fatty acid content between the flesh and peel in tomato. Others have reported fatty acid contents of 0.5 to $1.9 \mathrm{~g} / \mathrm{kg}$ in whole tomato (Gray and others 1999, USDA 2011). Differences in 
values can be accounted for by the different cultivars being used, storage conditions, as well as the known variation among individual tomatoes.

Table 4.5 Total fatty acid content ( $\mathrm{g}$ per fresh weight $\mathrm{kg}$ ) of different tomato varieties

\begin{tabular}{|l|c|c|}
\hline \multirow{2}{*}{} & \multicolumn{2}{|c|}{ Total Fatty Acid } \\
\cline { 2 - 3 } & Peel & Flesh \\
\hline Campari & $2.11^{\mathrm{abc}}$ & $1.50^{\mathrm{efg}}$ \\
\hline FG06-602 & $1.90^{\mathrm{bcde}}$ & $1.11^{\mathrm{gh}}$ \\
\hline Hydroponic & $2.41^{\mathrm{a}}$ & $2.00^{\mathrm{abcd}}$ \\
\hline Vine Ripened & $2.09^{\mathrm{abc}}$ & $0.90^{\mathrm{h}}$ \\
\hline Heirloom & $2.08^{\mathrm{abc}}$ & $1.68^{\mathrm{cdef}}$ \\
\hline Roma & $1.84^{\mathrm{bcde}}$ & $0.83^{\mathrm{h}}$ \\
\hline Grape & $1.95^{\mathrm{bcde}}$ & $1.61^{\mathrm{def}}$ \\
\hline Cherry & $1.73^{\mathrm{cde}}$ & $1.23^{\mathrm{fgh}}$ \\
\hline GEM 611 & $2.12^{\mathrm{abc}}$ & $1.57^{\mathrm{def}}$ \\
\hline F006-609 & $2.21^{\mathrm{ab}}$ & $2.12^{\mathrm{abc}}$ \\
\hline
\end{tabular}

${ }^{\mathrm{a}}$ Samples with different letters in the table are significantly different

The total fatty acid content includes linoleic, palmitic, linolenic, oleic, and stearic acids (Table 4.6). Linoleic acid (39-51\%) is present in the highest concentrations followed by palmitic acid (26-33\%). Linolenic (5-19\%) and oleic (4-19\%) acid concentrations vary by variety. Stearic acid (2-4\%) is always present at the lowest concentration. Others have reported that linoleic acid was present in the highest concentration followed by oleic acid, palmitic acid, then stearic acid or linolenic acid for the whole tomato or the pericarp (USDA 2010, Gray and others 2002). Linoleic acid is always reported to be present in the highest concentrations but the other fatty acids vary. 
The differences in order and percentages can be accounted for by a different cultivar being used, different tissue measured, as well as the known variation among tomatoes.

The peel contained significantly more linolenic acid than flesh in all varieties except two. For oleic acid, the flesh was significantly greater than peel for half of the varieties. Palmitic, stearic, and linoleic acids had minimal differences throughout the varieties. There have been no previous comparisons made for the fatty acids in the peel versus the flesh portions of a tomato.

Table 4.6 Fatty acid profiles $(\%)$ of different tomato varieties

\begin{tabular}{|c|c|c|c|c|c|c|}
\hline & & Linoleic Acid & Palmitic Acid & Linolenic Acid & Oleic Acid & Stearic Acid \\
\hline \multirow{2}{*}{ FG06-602 } & Flesh & $47.89^{\mathrm{ab}}$ & $30.96^{\mathrm{abcd}}$ & $12.11^{\mathrm{cde}}$ & $6.32^{\mathrm{gh}}$ & $2.71^{\mathrm{b}}$ \\
\hline & Peel & $39.62^{\mathrm{e}}$ & $33.96^{\mathrm{a}}$ & $19.15^{\mathrm{a}}$ & $4.08^{\mathrm{h}}$ & $3.19^{\mathrm{ab}}$ \\
\hline \multirow{2}{*}{ Vine Ripened } & Flesh & $40.41^{\mathrm{e}}$ & $32.60^{\mathrm{ab}}$ & $13.64^{\mathrm{bcd}}$ & $11.13^{\text {cdef }}$ & $2.81^{\mathrm{b}}$ \\
\hline & Peel & $39.19^{\mathrm{e}}$ & $30.83^{\mathrm{bcd}}$ & $14.66^{\mathrm{bc}}$ & $12.29^{\text {bcde }}$ & $2.85^{\mathrm{b}}$ \\
\hline \multirow{2}{*}{ Heirloom } & Flesh & $50.36^{\mathrm{a}}$ & $26.36^{\mathrm{ef}}$ & $7.03^{\mathrm{gh}}$ & $14.00^{\mathrm{bcd}}$ & $2.25^{\mathrm{b}}$ \\
\hline & Peel & $42.93^{\mathrm{de}}$ & $31.23^{\mathrm{abcd}}$ & $14.67^{\text {bcde }}$ & $8.25^{\mathrm{efg}}$ & $2.91^{\mathrm{b}}$ \\
\hline \multirow{2}{*}{ Roma } & Flesh & $46.41^{\mathrm{bc}}$ & $31.31^{\mathrm{abc}}$ & $8.99^{\text {efg }}$ & $8.83^{\mathrm{fgh}}$ & $4.46^{\mathrm{a}}$ \\
\hline & Peel & $44.71^{\mathrm{bcd}}$ & $28.67^{\mathrm{def}}$ & $16.42^{\mathrm{ab}}$ & $7.04^{\mathrm{gh}}$ & $3.16^{\mathrm{ab}}$ \\
\hline \multirow{2}{*}{ Grape } & Flesh & $46.12^{\mathrm{bcd}}$ & $26.18^{\mathrm{f}}$ & $5.18^{\mathrm{h}}$ & $19.47^{\mathrm{a}}$ & $3.05^{\mathrm{ab}}$ \\
\hline & Peel & $45.11^{\mathrm{bcd}}$ & $26.61^{\mathrm{ef}}$ & $9.41^{\mathrm{fg}}$ & $15.37^{\mathrm{b}}$ & $3.50^{\mathrm{ab}}$ \\
\hline \multirow{2}{*}{ Cherry } & Flesh & $50.45^{\mathrm{a}}$ & $29.19^{\mathrm{bcd}}$ & $8.63^{\text {fgh }}$ & $8.38^{\text {defg }}$ & $3.35^{\mathrm{ab}}$ \\
\hline & Peel & $51.72^{\mathrm{a}}$ & $30.27^{\text {cde }}$ & $10.55^{\text {defg }}$ & $4.47^{\mathrm{h}}$ & $2.99^{b}$ \\
\hline \multirow{2}{*}{ GEM 611} & Flesh & $43.07^{\text {cde }}$ & $31.29^{\mathrm{abcd}}$ & $9.45^{\mathrm{fg}}$ & $14.13^{\mathrm{bc}}$ & $2.05^{\mathrm{b}}$ \\
\hline & Peel & $41.16^{\mathrm{e}}$ & $33.92^{\mathrm{a}}$ & $17.03^{\mathrm{ab}}$ & $4.38^{\mathrm{h}}$ & $3.51^{\mathrm{ab}}$ \\
\hline
\end{tabular}

${ }^{a}$ Fatty acids with different letters in the same column are significantly different 
Even though fatty acids are present in small amounts they are the precursors for the lipid derived volatiles in the lipoxygenase pathway, which produces volatiles important to the green, fresh aroma of tomatoes (Petro-Turza 1987). Linolenic acid is converted into (Z)-3-hexenal as the first volatile produced from the pathway. Fatty acid content and amount of linolenic acid may affect the production of lipoxygenase generated volatiles such as (Z)-3-hexenal (Figure 4.2). There is a noticeable separation between the peel and flesh samples for both total fatty acid and linolenic acid content. Peel has higher concentrations of total fatty acids, linolenic acid, and (Z)-3-hexenal than flesh. Within the peel or flesh groups there is no significant correlation with lipid derived volatiles and either total fatty acid content or linolenic acid content.

There is some correlation between volatile levels and total fatty acid content for (Z)-3-hexenal, hexen-1-ol, (E)-2-hexenal, hexanal, and 1-hexanol. However, linolenic acid has a stronger correlation than total fatty acid content with (Z)-3-hexenal, (E)-2hexenal, and hexen-1-ol. Linoleic acid content had no correlation to hexanal and 1hexanol likely because there was no difference between peel and flesh linoleic acid content. For most of the lipid derived volatiles the correlation to total fatty acid content was the weakest with the correlations to lipoxygenase activity and linolenic content being similar (Figures 4.1 and 4.2). 

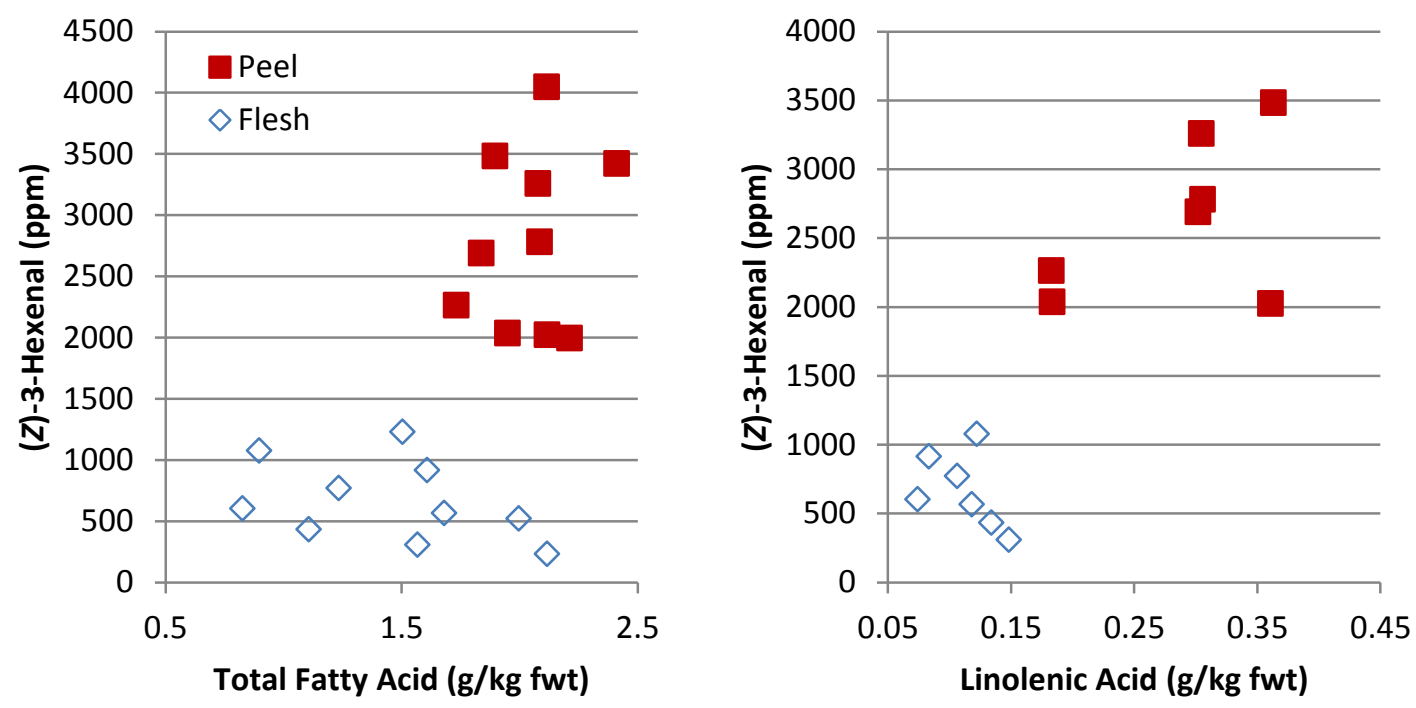

Figure 4.2 Effect of total fatty acid content (left) and linolenic acid (right) on (Z)-3-hexenal formation in flesh (diamond) and peel (square)

Exogenous linoleic acid was added to flesh and peel to test the effect on linoleic acid derived volatiles (Table 4.7). In the flesh, hexanal, 1-hexanol, and (E)-2-heptenal were significantly greater after linoleic acid addition. In the peel, only $(E)$-2-heptenal was greater. The difference in effect on peel versus flesh may mean that linoleic acid is the limiting factor in the flesh but not in the peel, since linoleic acid content is the same in flesh and peel but the lipoxygenase activity is significantly greater in the peel (Tables 4.3, 4.5 and 4.6). This is somewhat consistent with results of other studies that found an increase in the levels of hexanal and 1-hexanol in a whole tomato with the addition of linoleic acid (Boukobza and others 2001, Chen and others 2004, Riley and Thompson 1998). In green bell pepper, with the addition of linoleic acid there was a significant increase in the levels of hexanal, 1-hexanol, 2-pentylfuran, $(E)$-2-heptenal, $(E)$-2-octenal, 
(E)-2-nonenal and (Z)-3-hexenal (Luning and others 1995). With tomato cultivars that are bred to contain different levels of linoleic and linolenic acids, when the ratio of linoleic acid to linolenic acid is greater there is a significant increase in the hexanal to hexenal ratio (Gray and others 1999). Similar findings were found when the expression of a yeast $\Delta-9$ desaturase gene was altered to produce higher concentrations of oleic acid and linoleic acid, which caused hexanal and 1-hexanol to be more than two times greater than the control (Wang and others 1996). Breeding tomatoes with higher levels of linoleic acid and lower levels of linolenic acid caused an increase in hexanal and a decrease in (Z)-3-hexenal formation (Canoles and others 2006).

Table 4.7 Effect of linoleic acid addition on the formation of linoleic acid derived volatiles (ppm)

\begin{tabular}{|c|c|c|c|}
\hline & Volatile & Control & Sample with Addition \\
\hline \multirow{3}{*}{$\frac{\bar{y}}{\frac{e}{x}}$} & hexanal & $748^{\mathrm{b}}$ & $1393^{\mathrm{a}}$ \\
\hline & 1-hexanol & $6^{b}$ & $9^{a}$ \\
\hline & (E)-2-heptenal & $5^{b}$ & $28^{\mathrm{a}}$ \\
\hline \multirow{3}{*}{ ¿ } & hexanal & $3597^{\mathrm{a}}$ & $3243^{\mathrm{a}}$ \\
\hline & 1-hexanol & $28^{\mathrm{a}}$ & $19^{\mathrm{a}}$ \\
\hline & (E)-2-heptenal & $5^{b}$ & $26^{\mathrm{a}}$ \\
\hline
\end{tabular}

${ }^{\mathrm{a}}$ Samples with different letters in the same row are significantly different

\subsection{Variety Differences}

The variety differences in concentrations of volatiles are great. When samples were analyzed by chemometrics, the flesh and peel samples of any given variety were classified as closer together than peel or flesh samples between different varieties. Campari, FG06-602, and Grape had higher concentrations of volatiles than most varieties 
(Tables 4.1 and 4.2). Grape had significantly higher levels of (E)-2-heptenal and 1penten-3-one than any other variety, as well as noticeably higher levels of $(E)$-2-pentenal and acetaldehyde. Campari had concentrations significantly higher in cyclic terpenes and methyl benzoate with noticeably higher levels of (Z)-3-hexenal and 2-methylpropanal. There was no real pattern with the type of compounds, although 3 of the compounds having higher concentrations in Grape are produced in the lipoxygenase pathway. Interestingly, Grape and Campari are two of the smallest varieties of those measured. Results by Xu and Barringer (2010a) were similar in that grape tomato had higher levels of volatiles than vine-ripened, cherry and roma tomatoes. It was also reported that the formation of a mixture of (Z)-3-hexenal and (E)-2-hexenal during chewing is greater in cherry tomato than plum and delice tomatoes (Brauss and others 1998).

Each variety had major differences in which volatiles were significantly higher in peel than flesh (Tables 4.1 and 4.2). FG06-602, Vine Ripened, and Hydroponic had the greatest number of significantly greater peel volatiles than flesh volatiles with 19,18 , and 17 different volatiles respectively. The three varieties were significantly greater in 16 of the same volatiles. The different volatiles were fairly split between amino acid and lipid derived volatiles with slightly more being amino acid derived. Grape and GEM 611 had the least amount of volatile differences with only 3 and 4 volatiles, respectively. Neither Grape nor GEM 611 was significantly different in an amino acid derived volatile but were significantly different in lipid and pectin derived volatiles. 


\subsection{Effect of Storage Temperature on Volatiles}

\subsubsection{Day 0 vs. Day 14 Unrefrigerated and Refrigerated Storage}

Campari tomatoes were stored in unrefrigerated and refrigerated conditions for 14 days. Concentrations of volatiles, lipoxygenase activity and fatty acid content were measured at day 0 and day 14 . Stored unrefrigerated peel was significantly greater and refrigerated peel was significantly lower than before storage in hexanal, 1-hexanol, $(E)$-2-

hexenal, and dimethyl sulfide contents (Table 4.8). Refrigerated peel was also significant lower than day 0 in $(Z)-3$-hexenal. Overall, the flesh and peel showed the same trends but the flesh samples showed few significant differences which is possibly due to the overall levels being much lower. The increase in unrefrigerated peel volatiles is most likely due to ethylene production which allows the tomato to further ripen and continue producing flavor volatiles up until precursors are limiting. The exact mechanism by which the volatile concentrations decrease during refrigeration is unknown but could be related to reduced ethylene synthesis at low temperatures (Baldwin and others 2000). Other studies found similar results of those to refrigerated peel in that whole tomatoes stored at $5^{\circ} \mathrm{C}$ for 6 days had a significant decrease in volatiles with the main contributor being (Z)-3-hexenal (Stern and others 1994). After 2-12 days of storage at $5^{\circ} \mathrm{C}$, tomatoes had significantly lower ripe aroma and hexanal, 2+3-methylbutanol, (E)-2-heptenal, and 2-isobutylthiazole were at significantly lower concentrations than the tomatoes stored at 12.5 and $20^{\circ} \mathrm{C}$ (Maul and others 2000). 
Table 4.8 Effect of storage temperature on flesh and peel volatile production (ppm) after 14 days of storage

\begin{tabular}{|l|r|r|r|r|r|r|}
\hline & \multicolumn{3}{|c|}{ Peel } & \multicolumn{3}{c|}{ Flesh } \\
\cline { 2 - 7 } & Day 0 & Unrefrigerated & Refrigerated & Day 0 & Unrefrigerated & Refrigerated \\
\hline hexanal & $3743^{\mathrm{b}}$ & $5793^{\mathrm{a}}$ & $1705^{\mathrm{c}}$ & $809^{\mathrm{d}}$ & $1140^{\text {cd }}$ & $489^{\mathrm{d}}$ \\
\hline 1-hexanol & $26^{\mathrm{b}}$ & $35^{\mathrm{a}}$ & $17^{\mathrm{c}}$ & $5^{\mathrm{d}}$ & $7^{\mathrm{d}}$ & $4^{\mathrm{d}}$ \\
\hline$(E)$-2-heptenal & $7^{\mathrm{a}}$ & $5^{\mathrm{ab}}$ & $5^{\mathrm{ab}}$ & $5^{\mathrm{ab}}$ & $4^{\mathrm{b}}$ & $3^{\mathrm{b}}$ \\
\hline$(Z)$-3-hexenal & $3155^{\mathrm{a}}$ & $3538^{\mathrm{a}}$ & $2230^{\mathrm{b}}$ & $1103^{\mathrm{c}}$ & $1113^{\mathrm{c}}$ & $1017^{\mathrm{c}}$ \\
\hline$(E)$-2-hexenal & $319^{\mathrm{b}}$ & $430^{\mathrm{a}}$ & $215^{\mathrm{c}}$ & $151^{\mathrm{cd}}$ & $156^{\mathrm{cd}}$ & $144^{\mathrm{d}}$ \\
\hline$(Z)$-3-hexen-1-ol & $26^{\mathrm{ab}}$ & $34^{\mathrm{a}}$ & $21^{\mathrm{b}}$ & $9^{\mathrm{c}}$ & $9^{\mathrm{c}}$ & $9^{\mathrm{c}}$ \\
\hline$(E)$-2-pentenal & $39^{\mathrm{ab}}$ & $36^{\mathrm{ab}}$ & $40^{\mathrm{a}}$ & $41^{\mathrm{a}}$ & $26^{\mathrm{b}}$ & $41^{\mathrm{a}}$ \\
\hline 1-penten-3-one & $55^{\mathrm{b}}$ & $26^{\mathrm{b}}$ & $55^{\mathrm{b}}$ & $104^{\mathrm{a}}$ & $57^{\mathrm{b}}$ & $55^{\mathrm{b}}$ \\
\hline dimethyl sulfide & $544^{\mathrm{b}}$ & $896^{\mathrm{a}}$ & $280^{\mathrm{c}}$ & $145^{\mathrm{d}}$ & $206^{\mathrm{cd}}$ & $111^{\mathrm{d}}$ \\
\hline
\end{tabular}

${ }^{\text {a }}$ Samples with different letters in the same row are significantly different

${ }^{\mathrm{b}}$ Initial value before storage

\subsubsection{Storage Effects on Lipoxygenase Activity and Fatty Acid Content}

Storage decreased lipoxygenase activity in the unrefrigerated and refrigerated peel (Table 4.9). However, storage had no effect on the fatty acid content or flesh lipoxygenase activity. Due to the fact that fatty acid and flesh lipoxygenase activity did not change during storage they could not have played a role in the changing volatiles. Peel lipoxygenase activity was highest on before storage followed by the refrigerated and unrefrigerated samples, respectively. However, unrefrigerated peel had the highest levels of the lipoxygenase generated volatiles (E)-2-hexenal, (Z)-3-hexenal, hexanal, and 1hexanol followed by day 0 and refrigerated. This correlates with the fact that lipoxygenase was lower in refrigerated peel than in day 0 , but not with the fact that 
lipoxygenase activity was highest in unrefrigerated peel. Thus clearly other factors than lipoxygenase activity and fatty acid content also affect volatile production including temperature and rate of ethylene production.

Table 4.9 Effect of storage temperature on flesh and peel lipoxygenase activity (nmol/g fwt $/ \mathrm{min}$ ) and total fatty acid content $(\mathrm{g} / \mathrm{kg}$ fwt $)$ after 14 days of storage

\begin{tabular}{|l|l|c|c|}
\hline \multicolumn{2}{|c|}{} & $\begin{array}{l}\text { Lipoxygenase } \\
\text { Activity }\end{array}$ & $\begin{array}{l}\text { Fatty Acid } \\
\text { Content }\end{array}$ \\
\hline \multirow{3}{*}{$\bar{\Xi}$} & Day $0^{\mathrm{b}}$ & $67^{\mathrm{d}}$ & $1.49^{\mathrm{b}}$ \\
\cline { 2 - 4 } $\bar{\Sigma}$ & Unrefrigerated & $61^{\mathrm{d}}$ & $1.43^{\mathrm{b}}$ \\
\cline { 2 - 4 } & Refrigerated & $68^{\mathrm{d}}$ & $1.46^{\mathrm{b}}$ \\
\hline \multirow{3}{*}{$\Xi$} & Day $0^{\mathrm{b}}$ & $169^{\mathrm{a}}$ & $2.14^{\mathrm{a}}$ \\
\cline { 2 - 4 } & Unrefrigerated & $123^{\mathrm{c}}$ & $2.11^{\mathrm{a}}$ \\
\cline { 2 - 4 } & Refrigerated & $149^{\mathrm{b}}$ & $2.11^{\mathrm{a}}$ \\
\hline
\end{tabular}

${ }^{a}$ Samples with different letters in the same column are significantly different

${ }^{\mathrm{b}}$ Day 0 is the initial value before storage 


\section{Chapter 5: Conclusions}

Tomato peel had significantly higher concentrations of volatiles than flesh, when there was a significant difference. Lipoxygenase activity, total fatty acid content and linolenic acid content were also significantly greater in peel than in flesh for all varieties. Due to the high linolenic acid content of the peel there were higher levels of substrates to react with lipoxygenase producing an increase in successor molecules with an emphasis on (Z)-3-hexenal and other lipoxygenase generated volatiles. A correlation was identified between both lipoxygenase activity and linolenic acid content, and the formation of lipid derived volatiles. However, within peel or flesh groups, lipid derived compounds did not correlate well with total fatty acid content, lipoxygenase activity or linolenic acid. The addition of exogenous lipoxygenase had no effect on lipoxygenase derived volatiles formed in the peel and flesh, while the addition of linoleic acid caused an increase in hexanal, 1-hexanol, and $(E)$-2-heptenal in the flesh and $(E)$-2-heptenal in the peel. Stored unrefrigerated peel had the highest volatile concentrations followed by initial values at Day 0 then refrigerated peel, but this only partially matched changes in lipoxygenase activity while there was no change in the fatty acid content. Overall, linolenic acid was the most important to the formation of fresh, green volatiles, but lipoxygenase activity and unknown factors are clearly also important. 


\section{References}

Adams NG, Smith D. 1976. The selected ion flow tube (SIFT); a technique for studying ion-neutral reactions. Int J Mass Spectrom ion Phys 21:349-359.

Allendorf M, Subramanian A, Rodriguez-Saona L. 2011. Application of a handheld portable mid-infrared sensor for monitoring oil oxidative stability. J Am Oil Chem Soc 89(1):79-88.

Anthon GE. Personal communication. May 23, 2011.

AOAC. 1990. Official methods of analysis of association of official analytical chemists: food composition. Vol 11. In Helrich, K. (Ed.). Arlington: AOAC.

Azcarte C, Barringer SA. 2010. Effect of enzyme activity and frozen storage on jalapeno pepper volatiles by selected ion flow tube mass spectrometry. J Food Sci 75(9):710-721.

Baldwin EA, Scott JW, Shewmaker CK, Schuch W. 2000. Flavor trivia and tomato aroma: biochemistry and possible mechanisms for control of important aroma compounds. Hort Science 35(6): 1013-1022.

Beltran J, Serrano E, Lopez FJ, Peruga A, Valcarcel M, Rosello S. 2006. Comparison of two quantitative GC-MS methods for analysis of tomato aroma based on purgeand-trap and on solid-phase microextraction. Anal Bioanal Chem 385:1255-1264.

Bergevin M, L'Heureux GP, Thompson JE, Willemot C. 1993. Effect of chilling and subsequent storage at $20^{\circ} \mathrm{C}$ on electrolyte leakage and phospholipid fatty acid composition of tomato pericarp. Physiol Plant 87:522-527.

Bernalte MJ, Hernandez MT, Vidal-Aragon MC, Sabio E. 1998. Physical, chemical, flavor and sensory characteristics of two sweet cherry varieties grown in 'valle del jerte' (Spain). J Food Quality 22(4):403-416.

Bligh EG, Dyer WJ. 1959. A rapid method of total lipid extraction and purification. Can J Biochem Physiol 37:911-17.

Boukobza F, Dunphy PJ, Taylor AJ. 2001. Measurement of lipid oxidation-derived volatiles in fresh tomatoes. Postharvest Biol Tec 23(2):117-131.

Brauss MS, Linforth RS, Taylor AJ. 1998. Effect of variety, time of eating, and fruittofruit variation on volatile release during eating of tomato fruits (lycopersicon esculentum). J Agric Food Chem 46:2287-2292.

Buttery RG, Seifert RM, Guadagni DG, Ling LC. 1971. Characterization of additional components of tomato. J Agric Food Chem 19(3):524-529. 
Buttery RG, Teranishi R, Ling LC, Flath RA, Stern DJ. 1988. Quantitative studies on origins of fresh tomato aroma volatiles. J Agric Food Chem 36(6):1247-1250.

Buttery RG. 1993. Quantitative and sensory aspects of flavor of tomato and other vegetables and fruits. In: Acree TE, Teranishi R, editors. Flavor Science: Sensible Principles and Techniques. Washington DC: American Chemical Society. p 259286.

Buttery RG, Ling LC. 1993a. Enzymatic production of volatiles in tomatoes. In: Schreir P, Winterhalter P, editors. Flavor precursors. Wheaton IL: Allured Publications. $\mathrm{p}$ 137-146.

Buttery RG, Ling LC. 1993b. Volatiles of tomato fruit and plant parts: Relationship and biogenesis. In: Teranishi R, Buttery R, Sugisawa H, editors. Bioactive volatile compounds from plants. Washington DC: American Chemical Society. p 23-34.

Canoles MA, Beaudry RM, Li C, Howe G. 2006. Deficiency of linolenic acid in Lefad7 mutant tomato changes the volatile profile and sensory perception of disrupted leaf and fruit tissue. J Amer Soc Hort Sci 131(2):284-289.

Chen G, Hackett R, Walker D, Taylor A, Lin Z, Grierson D. 2004. Identification of a specific isoform of tomato lipoxygenase (Tomlox C) involved in the generation of fatty acid-derived flavor compounds. Plant Physiol 136:2641-2651.

Cook CC, Parsons CS, McCullough LP. 1958. Methods to extend storage of fresh vegetables aboard ships of the U.S. Navy. J Food Technol 12:548.

Cook D, Grierson D, Jones C, Wallace A, West G, Tucker G. 2002. Modification of fatty acid composition in tomato (Lycoperiscon esculentum) by expression of a borage $\Delta^{6}$-desaturase. Molec Biotechnol 21:123-128.

Davis BM, McEwan MJ. 2007. Determination of olive oil oxidative status by selected ion flow tube mass spectrometry. J Agric Food Chem 55(9):3334-3338.

Frank G. 2007. SIFT-MS: development of instrumentation and applications. [DPhil thesis]. Christchurch, New Zealand: Univ. of Canterbury. 91 p. Available from: ir.canterbury.ac.nz/bitstream/10092/3676/1/thesis_fulltext.pdf

Galliard T, Matthew JA. 1977. Lipoxygenase-mediated cleavage of fatty acids to carbonyl fragments in tomato fruits. Phytochemistry 16:339-343.

Galliard T, Matthew JA, Wright AJ, Fishwick MJ. 1977. The enzymic breakdown of lipids to volatile and non-volatile carbonyl fragments in disrupted tomato fruits. $\mathrm{J}$ Sci Food Agric 28:863-868.

Gibson EJ, Zhang Z, Baldwin JE, Schofield CJ. 1998. Substrate analogues and inhibition of ACC oxidase conversion of D-valine to iso-butanal. Phytochem 48(4):619-624.

Gray DA, Prestage S, Linforth RS, Taylor AJ. 1999. Fresh tomato specific fluctuations in the composition of lipoxygenase-generated C6 aldehydes. Food Chem 64: 149155 .

Hansanugrum A, Barringer S. 2009. Effect of milk on the deodorization of malodorous breath after garlic ingestion. J Food Sci 6:549-558.

Hansel A, Jordan A, Holzinger R, Prazeller P, Vogel W, Lindinger W. 1995. Int J of Mass Spectrom 149/150:609-619. 
Hardenburg RE, Watada AE, Wang CY. 1986. The commercial storage of fruits, vegetables and florist and nursery stocks. Agriculture Handbook Number 66, US Department of Agriculture.

Harper W, Wick C, Elekes K, Langford V, Kocaoglu-Vurma N. 2010. Analysis of volatile sulfur compounds in swiss cheese using selected ion flow tube mass spectrometry (SIFT-MS). ACS books: in press:1-52.

Hatanaka A, Kajiwara T, Matsui K, Kitamura A. 1992. Expression of lipoxygenase and hydroperoxide lyase activities in tomato fruits. Z Naturforsch 47c:369-374.

Hatanaka A. 1993. The biogeneration of green odour by green leaves. Phytochemistry 34:1201-1218.

Huang Y, Barringer S. 2010. Alkylpyrazines and other volatiles in cocoa liquors at ph 5 to 8 , by selected ion flow tube-mass spectrometry (SIFT-MS). J Food Chem (75)1:121-127.

Huang Y, Barringer S. 2011. Monitoring of cocoa volatiles produced during roasting by selected ion flow tube-mass spectrometry (SIFT-MS). Food Sci 76(2):C279C287.

Kazeniac SJ, Hall RM. 1970. Flavor chemistry of tomato volatiles. Food Sci 35:519-530.

Linforth RST, Ingham KE, Taylor AJ. 1996. Time course profiling of volatile release from foods during the eating process. In Flavour Science: recent developments. Cambridge: Royal Society of Chemistry. 361-368 p.

Longhurst TJ, Tung HF, Brady CJ. 1990. Developmental regulation of the expression of alcohol dehydrogenase in ripening tomato fruits. J Food Biochem 14:421-433.

Luning PA, Carey AT, Roozen JP, Wichers HJ. 1995. Characterization and occurrence of lipoxygenase in bell peppers at different ripening stages in relation to the formation of volatile flavor compounds. J Agric Food Chem 43:1493-1500.

Maul F, Sargent SA, Sims CA, Baldwin EA, Balaban MO, Huber DJ. 2000. Tomato flavor and aroma quality as affected by storage temperature. Food Sci 65(7):12281237.

Mayer F, Takeoka GR, Buttery RG, Whitehand LC, Naim M, Rabinowitch HD. 2008. Studies on the aroma of five fresh tomato cultivars and the precursors of cis- and trans-4,5-epoxy-(E)-2-decenals and methional. J Agric Food Chem 56:3749-3757.

Petro-Turza M. 1987. Flavor of tomato and tomato products. Food Rev Int 2(3):309-351.

Poll L, Flink JM. 1984. Aroma analysis of apple juice: influence of salt addition on headspace volatile composition as measured by gas chromatography and corresponding sensory evaluations. Food Chem 13: 193-207.

Prestage S, Linforth RS, Taylor AJ, Lee E, Speirs J, Schuch W. 1999. Volatile production in tomato fruit with modified alcohol dehydrogenase activity. J Sci Food Agric 79:131-136.

Rhodes MJC, Wooltorton LSC. 1967. The respiration climacteric in apple fruits.: The action of hydrolytic enzymes in peel tissue during the climacteric period in fruit detached from the tree. Phytochem 6(1):1-12.

Riley JC, Thompson JE. 1998. Ripening-induced acceleration of volatile aldehyde generation following tissue disruption in tomato fruit. Physiol Plant 104:571-576. 
Riley JC, Willemot C, Thompson JE. 1996. Lipoxygenase and hydroperoxide lyase activities in ripening tomato fruit. Postharvest Biol Tech 7:97-107.

Robertson LD, Labate JA. 2007. Genetic Resources of Tomato (Lycopersicon esculentum var. esculentum) and Wild Relatives. Genetic Improvement of Solanaceous Crops, Vol 2: Tomato. p. 25-75.

Senthilmohan ST, Milligan DB, McEwan MJ, Freeman CG, Wilson PF. 2000. Quantitative analysis of trace gases of breath during exercise using the new SIFTMS technique. Redox Rep 5(2-3):151-153.

Smith D, Spanel P. 1996. The novel selected-ion flow tube approach to trace gas analysis of air and breathe. Rapid Commun Mass Spectrom 10:1183-98.

Smith D, Wang T, Spanel V. 2003. Analysis of ketones by selected ion flow tube mass spectrometry. Rapid Commun Mass Spectrom 17:2655-2660.

Smith D, Wang T, Sule-Suso J, Spanel P, El Haj E. 2003. Quantification of acetaldehyde released by lung cnacer cells in vitro using selected ion flow tube mass spectrometry. Rapid Commun Mass Spectrom 17:845-850.

Smith D, Spanel P, Dabill D, Cocker J, Rajan B. 2004. On-line analysis of diesel engine exhaust gases by selected ion flow tube mass spectrometry. Rapid Commun Mass Spec 18(23):2830-2838.

Smith D, Spanel P. 2005. Selected Ion Flow Tube Mass Spectrometry (SIFT-MS) for online trace gas analysis. Mass Spectrom Review 24:661-700.

Spanel V, Doren, Smith D. 2002. A selected ion flow tube study of the reactions of $\mathrm{H}_{3} \mathrm{O}^{+}$, $\mathrm{NO}^{+}$, and $\mathrm{O}_{2}^{+}$with saturated and unsaturated aldehydes and subsequent hydration of the product ions. Int J Mass Spectrom 213:163-176.

Spanel P, Ji Y, Smith D. 1997. SIFT studies of the reactions of $\mathrm{H}_{3} \mathrm{O}^{+}, \mathrm{NO}^{+}$, and $\mathrm{O}_{2}^{+}$with a series of aldehydes and ketones. Int J Mass Spectrom 165/166:25-37.

Spanel P, Smith D. 1998a. Selected ion flow tube studies of the reactions of $\mathrm{H}_{3} \mathrm{O}^{+}, \mathrm{NO}^{+}$ and $\mathrm{O}_{2}{ }^{+}$with some organosulphur molecules. Int J Mass Spectrom 176:167-176.

Spanel P, Smith D. 1998b. SIFT studies of the reactions of $\mathrm{H}_{3} \mathrm{O}^{+}, \mathrm{NO}^{+}$and $\mathrm{O}_{2}^{+}$with a series of volatile carboxylic acids and esters. Int J Mass Spectrom 172: 137-147.

Spanel P, Smith D. 1999. Selected ion flow tube-mass spectrometry: detection and realtime monitoring of flavours released by food products. Rapid Commun Mass Spectrom 13:585-596.

Stern DJ, Buttery RG, Teranishi R, Ling L, Scott K, Cantwell M. 1994. Effect of storage and ripening on fresh tomato quality, part 1. Food Chem 49:225-231.

Stevens MA, Kader AA, Albright-Holton M. 1977. Intercultivar variation in composition of locular and pericarp portions of fresh market tomatoes. J Amer Soc Hort Sci 102(5):689-692.

Stone EJ, Hall RM, Kazeniac SJ. 1975. Formation of aldehydes and alcohols in tomato fruit from U-14 C labeled linolenic and linoleic acids. J Food Sci 40:1138-1141.

Storer MK, Hibbard-Melles K, Davis B, Scotter J. 2011. Detection of volatile compounds produced by microbial growth in urine by selected ion flow tube mass spectrometry (SIFT-MS). J Micro Methods 87(1):111-113.

Syft Technologies Inc. 2007. SIFT-MS technology overview [online]. New Zealand: Syft Technologies Inc, 2007 [cite 14 July 2011]. Available from World Wide Web: 
http://www.syft.com/images/Documents/Technology/syfttechnologyoverview1.3. pdf.

Syft Technologies. 2009. Kinetic library database. Christchurch, New Zealand: Syft Technologies Inc.

Urbach G. 1995. Contribution of lactic acid bacteria to flavor compound formation in dairy products. Int Dairy J 5:877-903.

U.S. Department of Agriculture. 2008. Tomatoes. Tomatoes at a Glance; Economic Research Service: Washington, DC.

U.S. Department of Agriculture, Agriculture Research Service. 2010. UDA National Nutrient Database for Standard Reference. Release 23. Nutrient Data Laboratory Home Page. http://www.ars.usda.gov/nutrientdata.

U.S. Department of Agriculture, Agriculture Research Service. 2011. UDA National Nutrient Database for Standard Reference. Release 24. Nutrient Data Laboratory Home Page. http://www.ars.usda.gov/nutrientdata.

Wang C, Chin CK, Ho CT, Hwang CF, Polashock J, Martin CE. 1996. Changes of fatty acids and fatty acid derived compounds by expressing the yeast $\Delta-9$ desaturase gene in tomato. J Agric Food Chem 44:3399-3402.

Wang T, Spanel P, Smith D. 2004. A selected ion flow tube study of the reactions of $\mathrm{H} 3 \mathrm{O}+, \mathrm{NO}+$ and $\mathrm{O} 2+$ with some phenols, phenyl alcohols and cyclic carbonyl compounds in support of SIFT-MS and PTR-MS. Int Mass Spectrom 239:139146.

Whitaker BD. 1993. Lipid changes in microsomes and crude plastid fractions during storage of tomato fruits at chilling and nonchilling temperatures. Phytochem 32(2):265-271.

Williams PJ. 1993. Hydrolytic flavor release in fruit and wines through hydrolysis of nonvolatile precursors. In: Acree TE, Teranishi R, editors. Flavor science: Sensible principles and techniques. Washington DC: American Chemical Society. p 287-308.

Wolford R, Banks D. 2011. Tomato [online]. Available from: http://urbanext.illinois.edu/veggies/tomato.cfm. [Accessed $2011 \mathrm{Jul} 18$ ].

Wong FF, Carson JF. 1966. Isolation of S-methyl methionine sulfonium salt from fresh tomatoes. J Agric Food Chem 14(3):247-249.

$\mathrm{Xu}$ Y, Barringer SA. 2009. Effect of temperature on lipid-related volatile production in tomato puree. J Agric Food Chem 57(19):9108-13.

$\mathrm{Xu}$ Y, Barringer S.2010a. Comparison of Tomatillo and Tomato Volatile Compounds in the Headspace by Selected Ion Flow Tube Mass Spectrometry (SIFT-MS). J Food Sci 75:268-273

$\mathrm{Xu}$ Y, Barringer S. 2010b. Comparison of volatile release in tomatillo and different varieties of tomato during chewing. J Food Sci 75:C352-C358.

Yilmaz E. 2001a. Oxylopin pathway in the biosynthesis of fresh tomato volatiles. Turk J Biol 25:351-360.

Yilmaz E. 2001b. Kinetic studies with crude tomato lipoxygenase. Turk J Agric For 25:291-296. 
Yilmaz E, Tandon KS, Scott JW, Baldwin EA, Shewfelt RL. 2001. Absence of a clear relationship between lipid pathway enzymes and volatile compounds in fresh tomatoes. J Plant Physiol 158:1111-1116.

Yilmaz E, Scott JW, Shewfelt RL. 2002. Effects of harvesting maturity and off-plant ripening on the activities of lipoxygenase, hydroperoxide lyase, and alcohol dehydrogenase enzymes in fresh tomato. J Food Biochem 26:443-457.

Zhuang H, Barth MM, Hilderbrand DF. 1998. Fatty acid oxidation in plant tissues. In Food Lipids: Chemistry, Nutrition and Biotechnology. New York: Marcel Dekker. p 333-375. 